\title{
Demetalation of Copper Undecaarylcorroles: Molecular Structures of a Free-Base Undecaarylisocorrole and a Gold Undecaarylcorrole
}

\author{
Jan Capar, ${ }^{a}$ Job Zonneveld, ${ }^{a}$ Steffen Berg, ${ }^{a}$ Johan Isaksson, ${ }^{a}$ Kevin J. Gagnon, ${ }^{b}$ \\ Kolle E. Thomas, ${ }^{* a}$ and Abhik Ghosh*,a
}

\begin{abstract}
${ }^{a}$ Department of Chemistry and Center for Theoretical and Computational Chemistry, University of Troms $\varnothing$, N-9037 Troms $\varnothing$, Norway; Email: thomas.kolle@uit.no; abhik.ghosh@uit.no; ${ }^{b}$ Advanced Light Source, Lawrence Berkeley National Laboratory, Berkeley, CA 94720-8229
\end{abstract}

\begin{abstract}
Copper undecaarylcorroles were found to undergo acid-induced demetalation with unusual ease under both reductive and nonreductive conditions. The resulting free-base undecaarylcorroles were found to be rather reactive, readily photooxygenating to yield 5/10hydroxyisocorroles and open-chain tetrapyrroles. The use of nonreductive conditions led to fairly good yields of undecaarylisocorroles, a new class of sterically hindered ligands, of which one proved amenable to single-crystal X-ray structural analysis. In one case, interaction of an undecaarylisocorrole with gold(III) acetate resulted in aromatization of the macrocycle and a gold undecaarylcorrole. The Au complex exhibited Au-N distances of 1.941(3)-1.965(3) A, and no significant nonbonded interactions involving the gold. The significant solubility of this complex in organic solvents, compared with the relative insolubility of gold $\beta$-octabromo-mesotriarylcorroles, appears to be related to the lack of aurophilic and metallophilic interactions.
\end{abstract}


Introduction. Metallocorroles, ${ }^{[1,2,3,4]}$ particularly copper corroles, are typically much more readily functionalized and elaborated in a controlled manner than free-base corroles. Subsequent demetalation then has the potential to yield novel, substituted free-base corrole ligands. Unfortunately, the demetalation of metallocorroles is generally more difficult than that of common metalloporphyrins, requiring both strong acid and an excess of a reductant such as a $\mathrm{Fe}(\mathrm{II})$ or $\mathrm{Sn}(\mathrm{II})$ salt. $^{[5,6,7,8,9,10]}$ A notable success of this 'reductive demetalation' approach has been the synthesis of free-base $\beta$-octabromocorroles ${ }^{[7,6,9,11]}$ and their subsequent use as ligands. ${ }^{12,13,14]}$ Here we report that copper undecaarylcorroles ${ }^{[15,16,17]}$ demetalate with unusual ease, in a matter of minutes, on exposure to acid, under both reductive and nonreductive conditions.

In what initially appeared to be a setback, free-base undecaarylcorroles were found to be rather reactive, readily reacting with ambient oxygen to generate 5-hydroxy- and 10-hydroxyundecaarylisocorroles as well as open-chain dioxo compounds. As shown in Figure 1, isocorroles are fascinating ligands in their own right: they are porphyrin-like by virtue of their diprotic or dianionic character and corrole-like in affording a spatially constricted cavity for metal coordination. ${ }^{[18,19,20,21,22]}$ They are thus promising platforms for unusual transition metal spin states. In a pertinent study, Bröring and coworkers have reported that thiacorroles, which are structurally similar to isocorroles, give rise to intermediate-spin iron(III) complexes. ${ }^{[23]} \mathrm{A}$ second remarkable feature of isocorroles is their strong absorption in the near-infrared, ${ }^{\left[{ }_{21}\right]}$ which is of great relevance to photodynamic therapy. ${ }^{[24]}$ Reported herein are optimized syntheses for a family of sterically hindered undecaarylisocorrole ligands, including the first, single-crystal X-ray structure of a free-base undecaarylisocorrole.

Furthermore, we have attempted to determine whether undecaarylisocorrole ligands can be rearomatized on metal complexation, yielding novel undecaarylcorrole complexes. This is an important question because, as of today, only copper and cobalt undecaarylcorroles have been reported..$^{\left[5^{-17}\right]}$ New metalloundecaarylcorroles are of considerable interest as shape-selective catalysts and other functional materials. As shown in Figure 2, we found that at least one freebase undecaarylisocorrole could be smoothly converted to the corresponding gold undecaarylcorrole. The same gold complex could also be obtained from a gold $\beta$-octabromomeso-triarylcorrole via a tedious, week-long Suzuki coupling procedure. Remetalation and aromatization of isocorroles to corroles, when feasible, thus promises to be a useful transformation. 


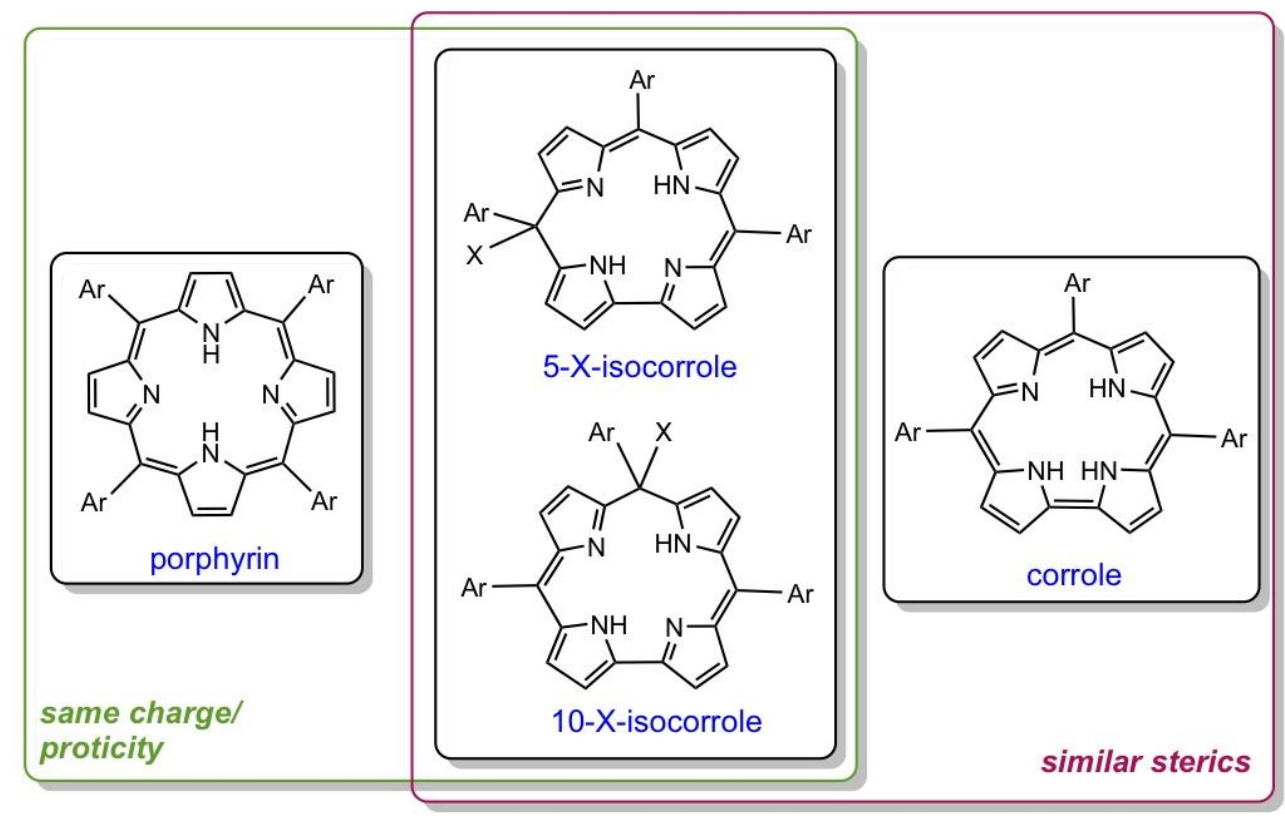

Figure 1. Steric and electronic relationships between porphyrin, corrole, and isocorrole ligands.

Whereas porphyrin and isocorroles share the same proticity (both coordinate as dianionic ligands), isocorroles and corroles share similar, constricted coordination cavities.

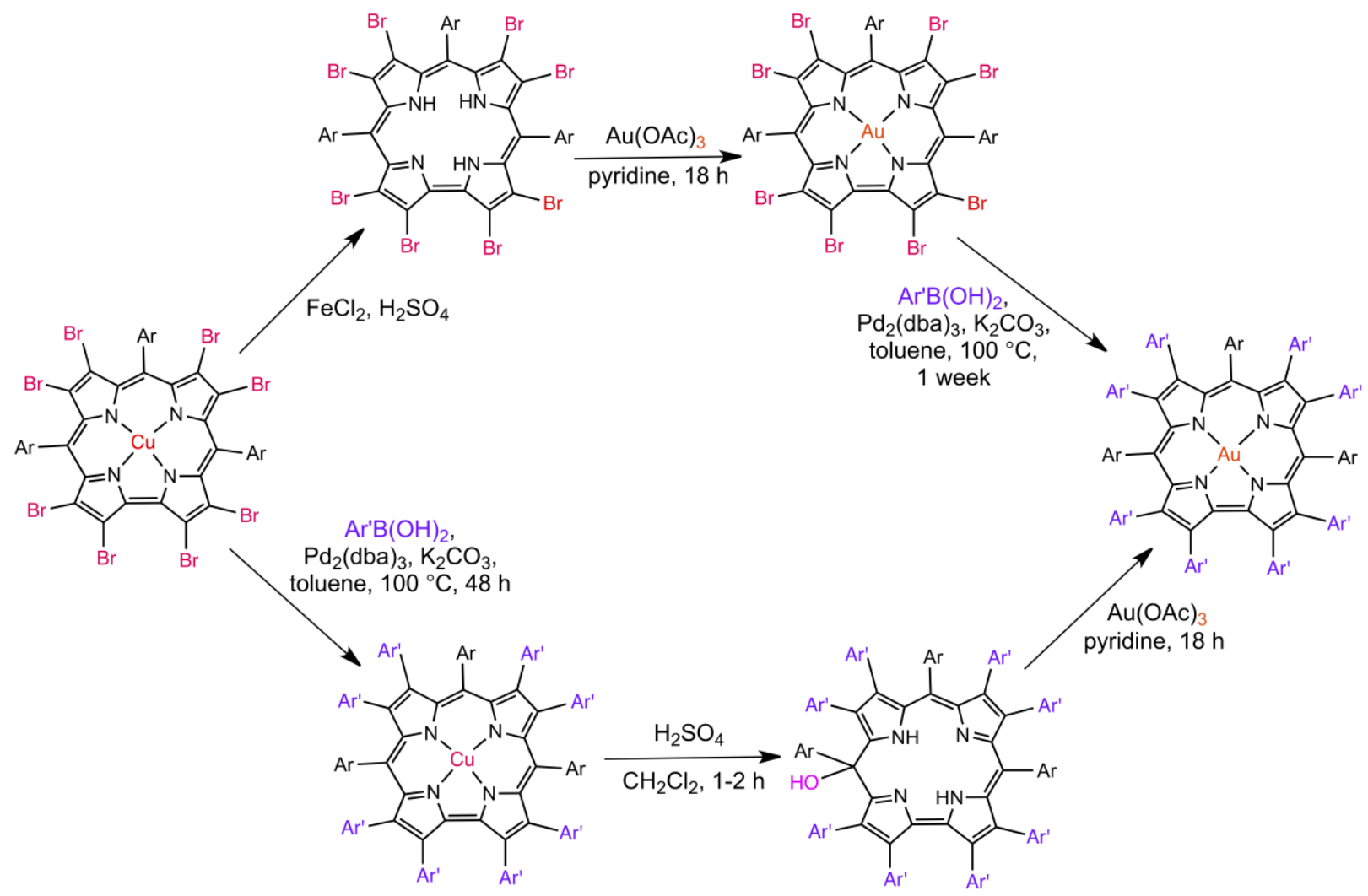

Figure 2. Two alternative synthetic routes to the gold undecaarylcorrole $\mathrm{Au}\left[\left(\mathrm{CF}_{3}\right)_{8} \mathrm{H}_{3}\right]$. 


\section{Results and Discussion}

(a) Demetalation of copper undecaarylcorroles and isocorrole formation. Four different copper undecaarylcorroles were demetallated in this study, copper $\beta$-octakis $(p-\mathrm{X}$ phenyl)-meso-tris ( $p$-methylphenyl)corrole, where $\mathrm{X}=\mathrm{H}, \mathrm{F}$, and $\mathrm{CF}_{3}$, and copper $\beta$-octakis $(p$ trifluoromethylphenyl)-meso-triphenylcorrole (Figure 3). For brevity, we will refer to these complexes as $\mathrm{Cu}\left[\mathrm{X}_{8} \mathrm{Me}_{3}\right]$. We will also refer to the corresponding free-base corroles as $\mathrm{H}_{3}\left[\mathrm{X}_{8} \mathrm{Me}_{3}\right]$ and the isocorroles as $\mathrm{H}_{2}\left[\mathrm{X}_{8} \mathrm{Me}_{3}(5-\mathrm{OH})\right]$. Reductive demetalation of $\mathrm{Cu}\left[\mathrm{X}_{8} \mathrm{Me}_{3}\right]$ with concentrated sulfuric acid and $\sim 10$ equiv of anhydrous $\mathrm{FeCl}_{2}$ led to $\sim 70 \%$ yields of the free-base corroles, $\mathrm{H}_{3}\left[\mathrm{X}_{8} \mathrm{Me}_{3}\right]$, in a matter of minutes, but in the presence of air and light, free-base undecaarylcorroles quickly decomposed to open-chain dioxotetrapyrroles and small quantitites of the isocorroles, $\mathrm{H}_{2}\left[\mathrm{X}_{8} \mathrm{Me}_{3}(5 / 10-\mathrm{OH})\right]$. Eliminating reductive conditions (i.e., $\mathrm{FeCl}_{2}$ ) proved to be an effective way of improving the yield of isocorroles, the key targets of this study, as did the presence of an organic solvent such as dichloromethane. The final optimized conditions, involving demetalation in dichloromethane and concentrated sulfuric acid, led to 50-65\% yields of highly stable, free-base isocorroles, with negligible quantities of corroles and open-chain tetrapyrroles.

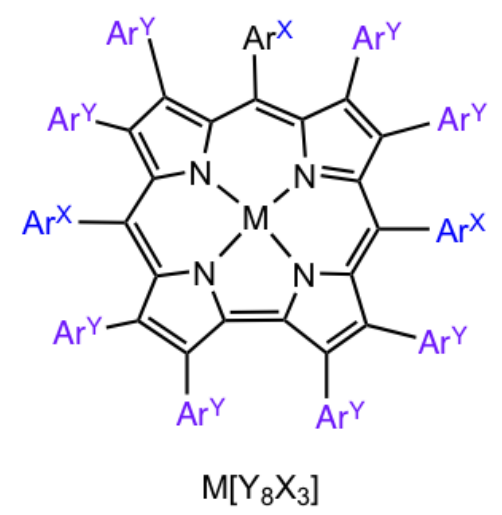

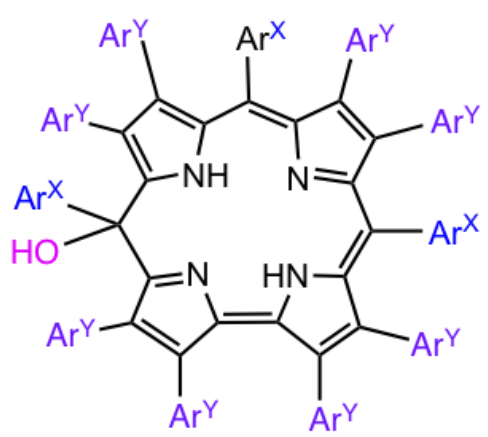

$\mathrm{H}_{2}\left[\mathrm{Y}_{8} \mathrm{X}_{3}(5-\mathrm{OH})\right]$

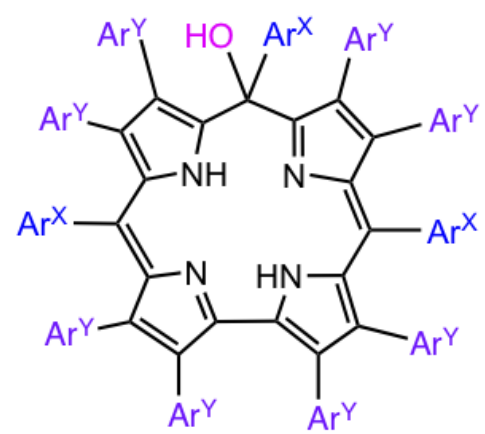

$\mathrm{H}_{2}\left[\mathrm{Y}_{8} \mathrm{X}_{3}(10-\mathrm{OH})\right]$

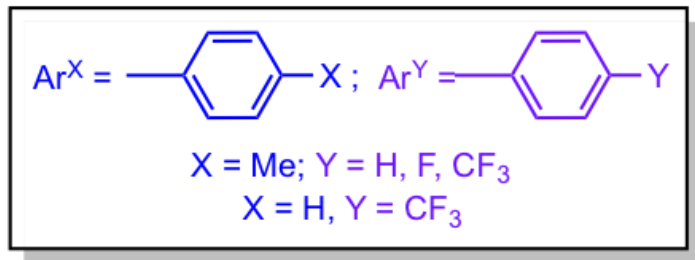

Figure 3. Corrole and isocorrole derivatives investigated in this study. 
Each demetalation led to both 5- and 10-OH isocorroles, with the former dominating. Although not separable by column chromatography, the two regioisomers could be separated by preparative thin-layer chromatography. Except for one case, $\mathrm{H}_{2}\left[\left(\mathrm{CF}_{3}\right)_{8} \mathrm{Me}_{3}(10-\mathrm{OH})\right]$, however, the pure 10-regioisomer was not obtained in large enough quantities for full characterization. Figure 4 presents the UV-vis absorption spectra of these two isomeric compounds; note the intense Soretlike features, despite the lack of aromaticity, and strong absorption in the red and near-infrared. Examples of preferential formation of one or the other regioisomer well-documented in the literature. ${ }^{[25,26,27]}$ Thus, a convenient isocorrole synthesis, involving DDQ oxidation of mesotriarylcorroles in methanol, was found to lead preferentially to 5-OMe isocorroles. ${ }^{[22]}$ On the other hand, nonreductive demetalation of $\mathrm{Cu}\left[\mathrm{Br}_{8} \mathrm{H}_{3}\right]$ (i.e., copper $\beta$-octabromo-meso-triphenylcorrole) with $\mathrm{H}_{2} \mathrm{SO}_{4} / \mathrm{CHCl}_{3}$ led to preferential formation of the $10-\mathrm{OH}$ isocorrole, $\mathrm{H}_{2}\left[\mathrm{Br}_{8} \mathrm{H}_{3}(10-\mathrm{OH})\right]$. ${ }^{\left[{ }_{5}\right]} \mathrm{A}$ combination of electronic and steric factors is presumably responsible for the preponderance of one isomer over the other.

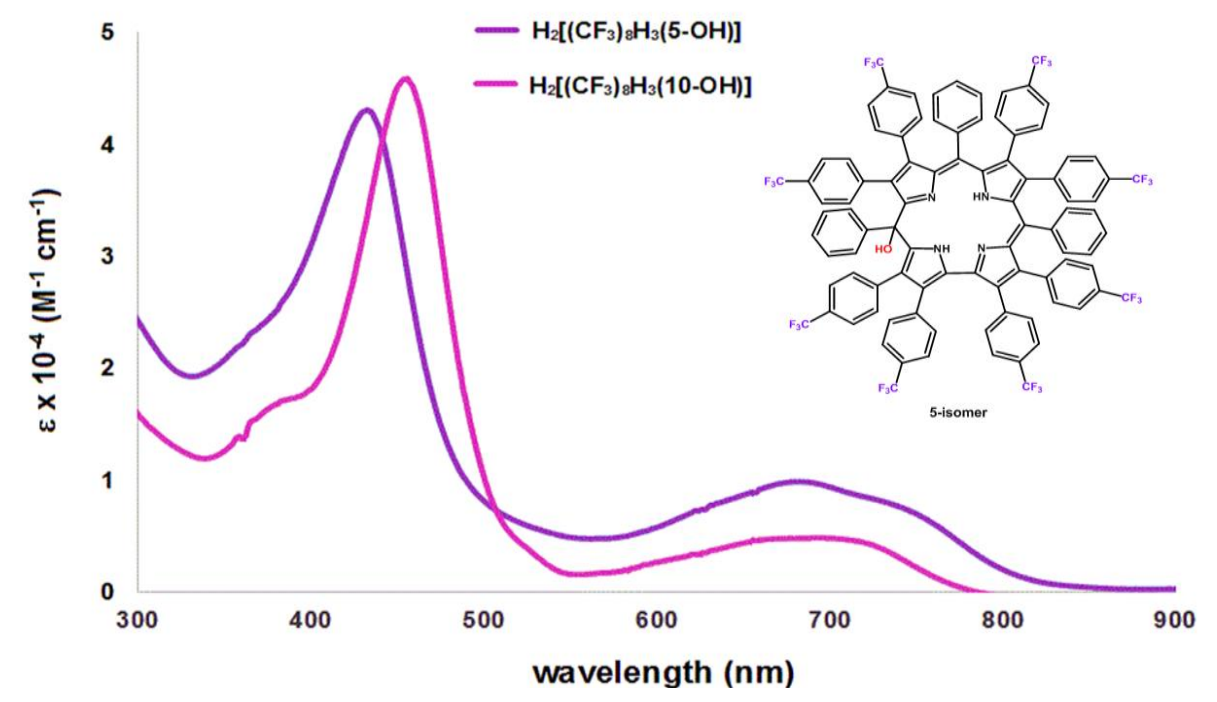

Figure 4. UV-vis spectra of $\mathrm{H}_{2}\left[\left(\mathrm{CF}_{3}\right)_{8} \mathrm{H}_{3}(5-\mathrm{OH})\right]$ and $\mathrm{H}_{2}\left[\left(\mathrm{CF}_{3}\right)_{8} \mathrm{H}_{3}(10-\mathrm{OH})\right]$.

Literature reports suggest that the oxygen in 5/10-OH isocorroles arises from $\mathrm{O}_{2}$ rather than water, although the latter has not been strictly ruled out. ${ }^{\left[{ }_{6,27}\right]}$ To determine the source of oxygen in the isocorroles obtained in this study, we carried out isotope labeling experiments with $\mathrm{H}_{2}{ }^{18} \mathrm{O}$ and ${ }^{18} \mathrm{O}_{2}$. The freshly purified, vacuum-dried corrole $\mathrm{H}_{3}\left[\left(\mathrm{CF}_{3}\right)_{8} \mathrm{Me}_{3}\right]$, upon stirring in anhydrous dichloromethane and $\mathrm{H}_{2}{ }^{18} \mathrm{O}$ under argon, showed no evidence of ${ }^{18} \mathrm{O}$ incorporation with electrospray ionization (ESI) mass spectrometry (MS). In contrast, bubbling ${ }^{16} \mathrm{O}_{2}$ into a solution of pure $\mathrm{H}_{3}\left[\left(\mathrm{CF}_{3}\right)_{8} \mathrm{Me}_{3}\right]$ in anhydrous dichloromethane revealed the incorporation of both 
one and two oxygen atoms via ESI-MS. Flushing the ESI mass spectrometer with ${ }^{18} \mathrm{O}_{2}$ also resulted in the incorporation of both one and two ${ }^{18} \mathrm{O}$ atoms into $\mathrm{H}_{3}\left[\left(\mathrm{CF}_{3}\right)_{8} \mathrm{Me}_{3}\right]$, confirming the strong affinity of free-base undecaarylcorroles for dioxygen. One plausible pathway for the oxidative decomposition of free-base corroles, based on both literature precedence ${ }^{[26,27,28,29]}$ and our own experiments, is depicted in Figure 5.

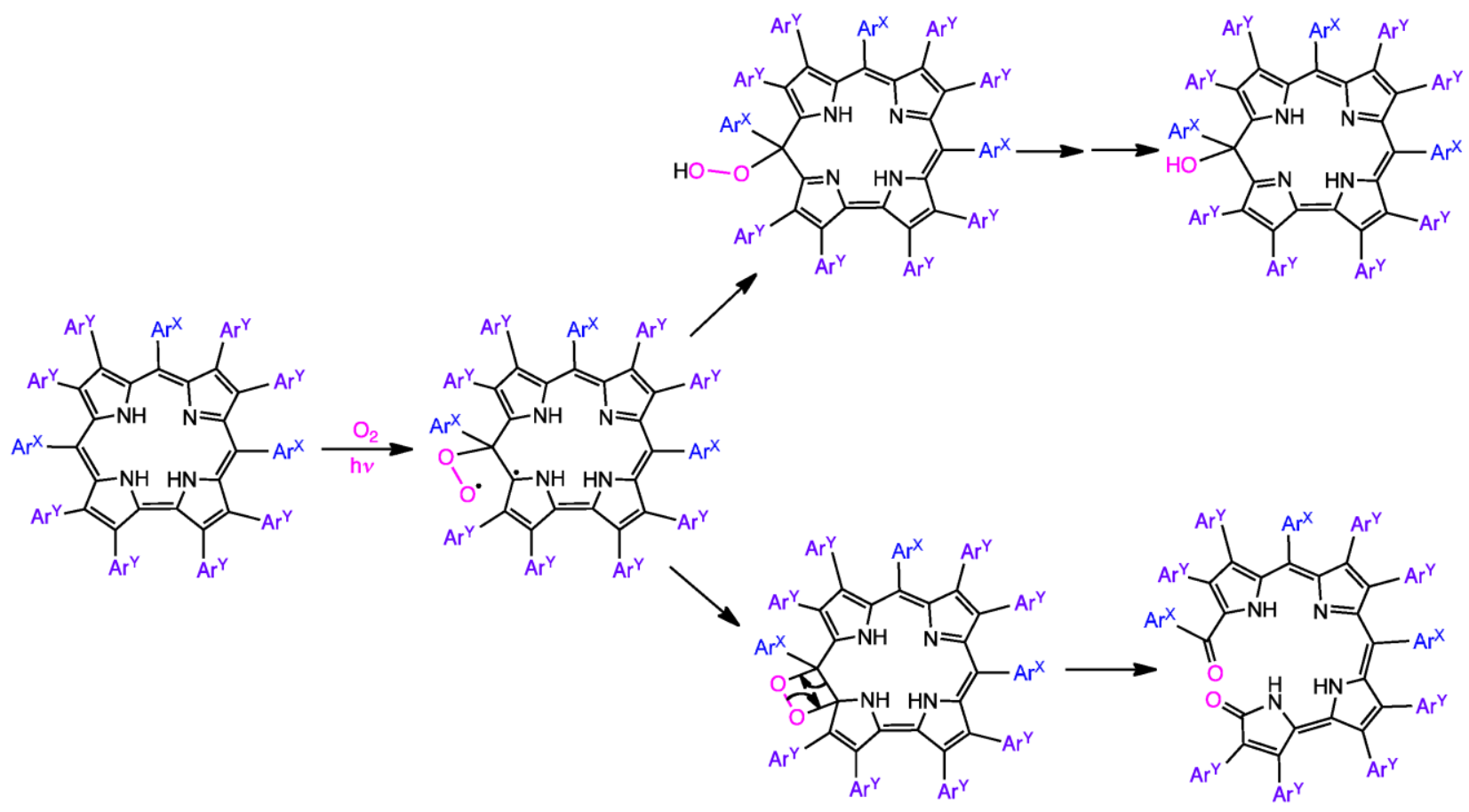

Figure 5. Proposed pathway for photooxygenation of a free-base undecaarylcorrole. Analogous mechanisms can be drawn for $\mathrm{O}_{2}$ attack at the 2- and 10- positions.

A single-crystal X-ray structure could be obtained for the free-base undecaarylisocorrole $\mathrm{H}_{2}\left[\left(\mathrm{CF}_{3}\right)_{8} \mathrm{Me}_{3}(5-\mathrm{OH})\right]$ (Figure 6, Table 1). Despite the considerable steric crowding, the macrocyclic skeleton of $\mathrm{H}_{2}\left[\left(\mathrm{CF}_{3}\right)_{8} \mathrm{Me}_{3}(5-\mathrm{OH})\right]$ was found to be essentially planar, as for other free-base isocorroles, but in sharp contrast to free-base corroles, which are generally strongly buckled as a result of steric repulsion among the three inner hydrogens. ${ }^{[30,31]}$ The two central hydrogens of $\mathrm{H}_{2}\left[\left(\mathrm{CF}_{3}\right)_{8} \mathrm{Me}_{3}(5-\mathrm{OH})\right]$ could be unambiguously located from the difference map. The skeletal bond distances, which are broadly similar to those observed for other 5-isocorrole structures, ${ }^{[21,25]}$ are consistent with strong localization of single and double bonds, with no significant indication of homoaromaticity. 

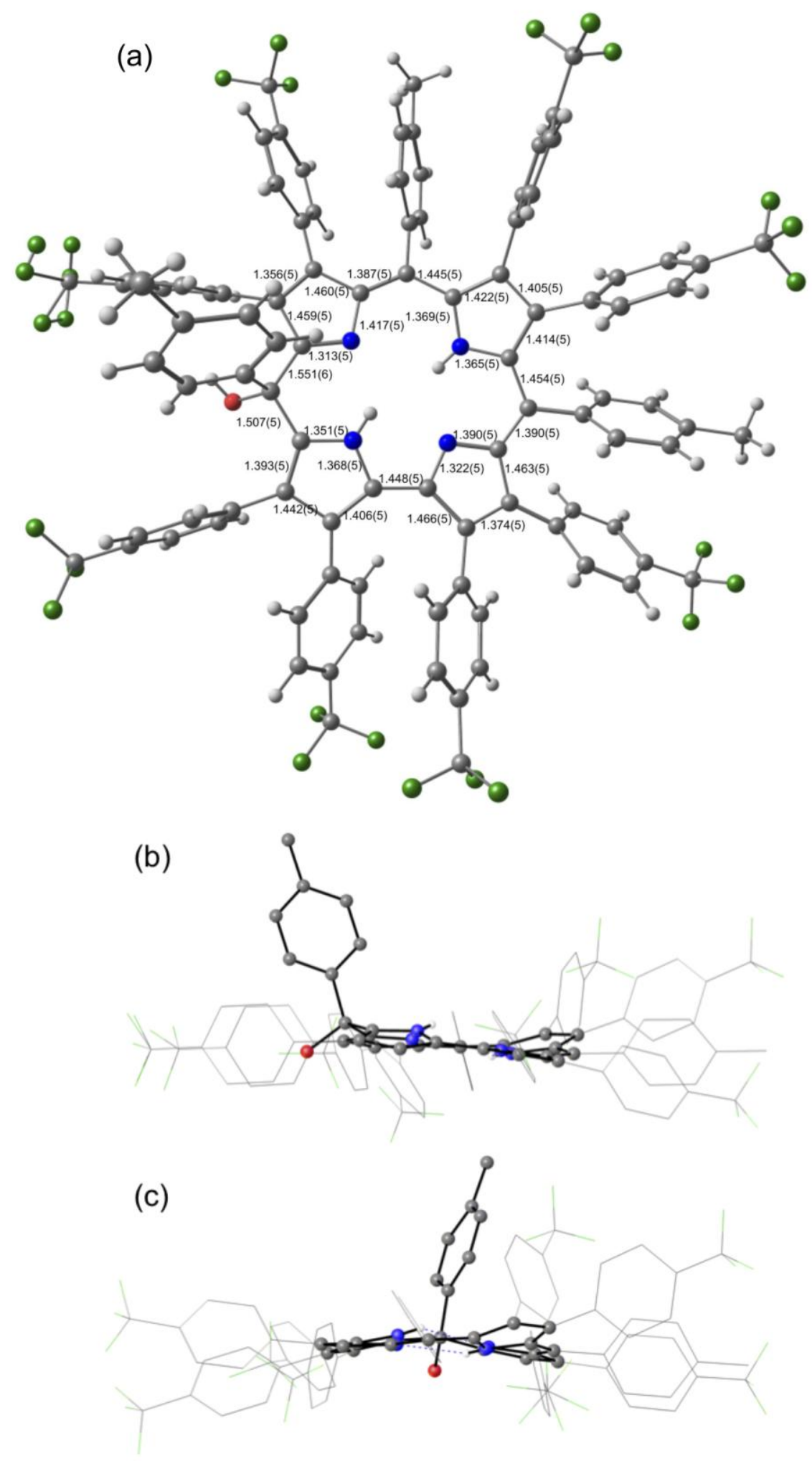

Figure 6. X-ray structure of free-base undecaarylisocorrole $\mathrm{H}_{2}\left[\left(\mathrm{CF}_{3}\right)_{8} \mathrm{Me}_{3}(5-\mathrm{OH})\right]$ : (a) top view with skeletal bond distances $(\AA)$ and (b, c) side views. Note to printer: Please reproduce using a full journal page to ensure the small text within the figure is legible. 
Table 1. Crystallographic data for $\mathrm{H}_{2}\left[\left(\mathrm{CF}_{3}\right)_{8} \mathrm{Me}_{3}(5-\mathrm{OH})\right]$.

\begin{tabular}{ccc}
\hline Sample & $\mathrm{H}_{2}\left[\left(\mathrm{CF}_{3}\right)_{8} \mathrm{Me}_{3}(5-\mathrm{OH})\right]$ & $\mathrm{Au}\left[\left(\mathrm{CF}_{3}\right)_{8} \mathrm{H}_{3}\right]$ \\
\hline Chemical formula & $\mathrm{C}_{96} \mathrm{H}_{56} \mathrm{~F}_{24} \mathrm{~N}_{4}$ & $\mathrm{C}_{95} \mathrm{H}_{51} \mathrm{~F}_{24} \mathrm{~N}_{4} \mathrm{Cl}_{4} \mathrm{Au}$ \\
Formula mass & 1737.44 & 2043.16 \\
Crystal system & Triclinic & Triclinic \\
Space group & $P 1$ & $P-1$ \\
$\lambda(\AA)$ & 0.7749 & 0.7749 \\
$a(\AA)$ & $12.783(3)$ & $15.4998(6)$ \\
$b(\AA)$ & $18.085(4)$ & $16.8410(6)$ \\
$c(\AA)$ & $18.600(4)$ & $16.9639(6)$ \\
$\alpha($ deg. $)$ & $102.363(3)$ & $106.229(2)$ \\
$\beta($ deg. $)$ & $108.203(3)$ & $91.961(2)$ \\
$\gamma($ deg. $)$ & $96.468(3)$ & $106.901(2)$ \\
$Z$ & 2 & 2 \\
V $\left(\AA^{3}\right)$ & $3914.7(15)$ & $4035.8(3)$ \\
Temperature $(\mathrm{K})$ & $100(2)$ & $100(2)$ \\
Density $\left(\mathrm{g} / \mathrm{cm}^{3}\right)$ & 1.474 & 1.681 \\
Measured reflections & 40303 & 78866 \\
Unique reflections & 15237 & 29236 \\
Parameters & 1169 & 1256 \\
Restraints & 66 & 646 \\
$\mathrm{R}_{\text {int }}$ & 0.0670 & 0.0524 \\
$\theta$ range (deg.) & $2.587-28.553$ & $2.165-36.007$ \\
$\mathrm{R}_{1}$, wR $\mathrm{R}_{2}$ all data & $0.0683,0.2226$ & 1.030 \\
$\mathrm{~S}$ (GooF) all data & 1.024 & $2.151 /-1.956$ \\
Max/min res. Dens. $\left(\mathrm{e} / \AA^{3}\right)$ & $0.410 /-0.349$ & \\
\hline min & &
\end{tabular}

(b) Synthesis and molecular structure of a gold undecaarylcorrole. Given the

oxidative instability of free-base undecaarylcorroles, we were intrigued by the question whether metal insertion into a free-base undecaarylisocorrole might proceed with concomitant aromatization, thereby providing a pathway to novel metalloundecaarylcorroles. Although a full exploration of this question, involving different isocorroles and metal ions, has not yet been carried out, we were gratified to discover that interaction of free-base $\mathrm{H}_{3}\left[\left(\mathrm{CF}_{3}\right)_{8} \mathrm{H}_{3}(5-\mathrm{OH})\right]$ and gold(III) acetate in pyridine leads to the fully aromatized undecaarylcorrole complex $\mathrm{Au}\left[\left(\mathrm{CF}_{3}\right)_{8} \mathrm{H}_{3}\right]$ in yields of $\sim 40 \% .{ }^{[32,33]} \mathrm{We}$ are currently examining the generality of this process and will report on our findings in due course.

Unlike many gold $\beta$-octabromocorrole complexes, which tend to be quite insoluble, presumably because of intermolecular metallophilic $\mathrm{Au}$... Br interactions, ${ }^{32} \mathrm{Au}\left[\left(\mathrm{CF}_{3}\right)_{8} \mathrm{H}_{3}\right]$ was 
found to be moderately soluble. X-ray quality crystals were obtained and single-crystal structure determination revealed a planar Au corrole, Au-N distances of 1.941(3)-1.965(3) $\AA$, and no significant nonbonded interactions involving the gold (Figure 6). ${ }^{[34]}$ The planarity of the gold corrole may be contrasted with the strong nonplanarity of copper corroles, which is believed to be due to ligand noninnocence. Silver corroles exhibit more variable behavior in this regard. Thus, whereas simple silver meso-triarylcorroles are only slightly saddled, ${ }^{[35]}$ a recent X-ray structure has provided an example of a strongly saddled silver $\beta$-octabromocorrole. ${ }^{[36]}$ The substantial variations in corrole geometry in the silver case have been attributed to variations in noninnocent character among the different ligands. By contrast, corrole ligands in gold corroles are thought to be innocent.

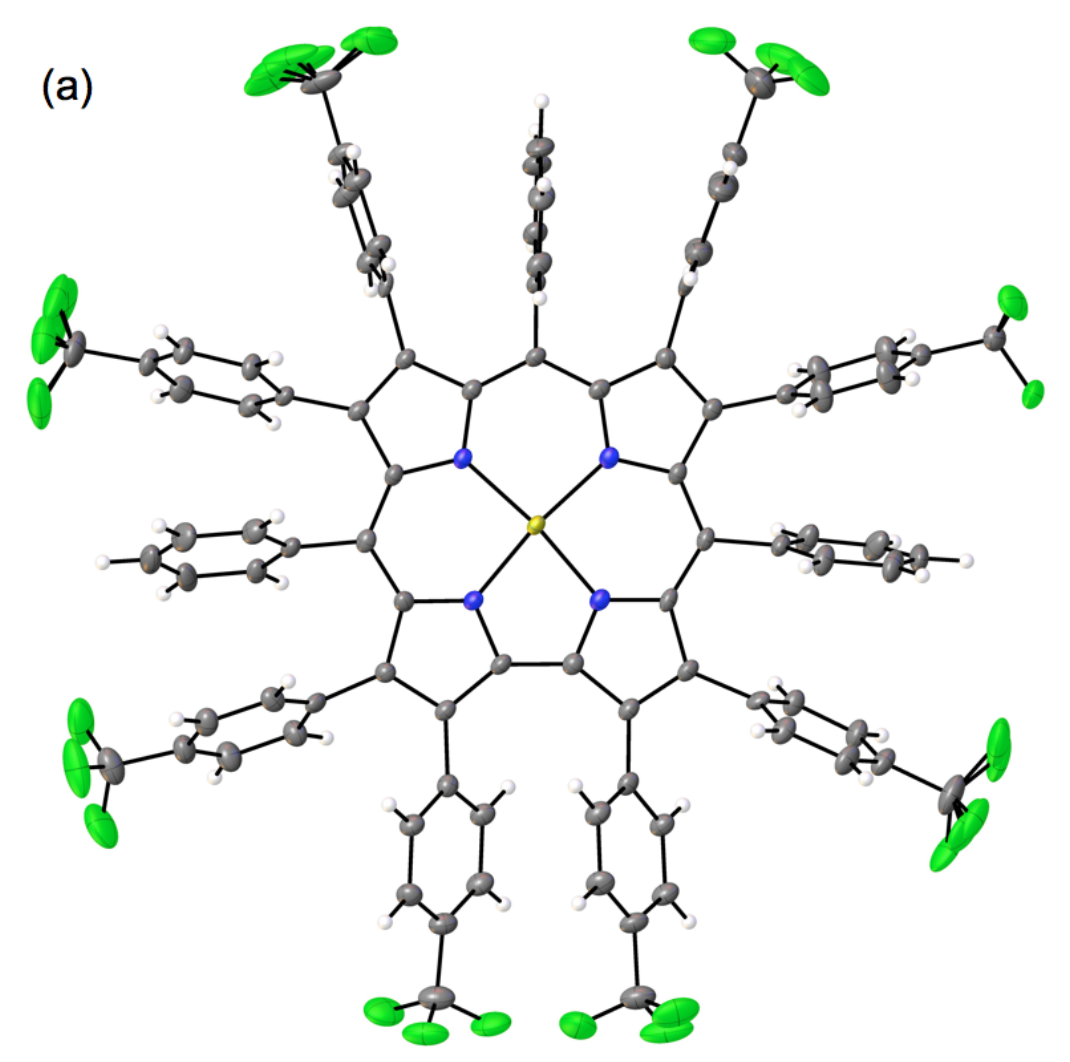

(b)

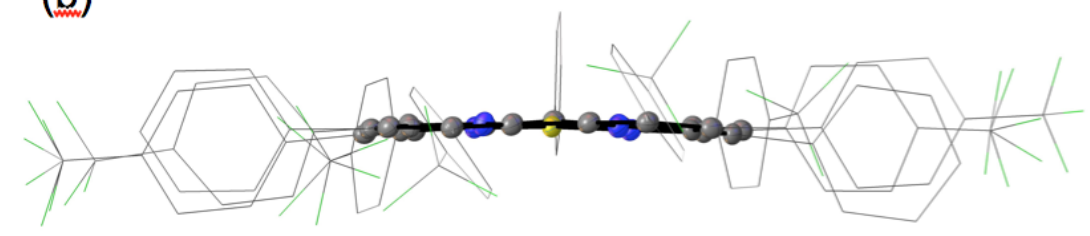

Figure 7. X-ray structure of the gold undecaarylcorrole $\mathrm{Au}\left[\left(\mathrm{CF}_{3}\right)_{8} \mathrm{H}_{3}\right]$ : (a) top view and (b) side view. 


\section{Conclusion}

In summary, copper undecaarylcorroles were found to demetallate with unusual ease under standard reductive demetalation conditions. The free-base undecaarylcorroles, however, proved to be light- and oxygen-sensitive, readily oxidizing to open-chain dioxotetrapyrroles and $5 / 10-\mathrm{OH}$ isocorroles. Nonreductive conditions could be devised that led to good yields $65-80 \%$ of 5/10-OH undecaarylisocorroles, a new class of sterically hindered and relatively stable macrocyclic ligands. Interaction of one such ligand with gold(III) acetate resulted in rearomatization of the macrocycle and a gold undecaarylcorrole, which proved amenable to single-crystal X-ray diffraction analysis. Unlike the rather insoluble gold $\beta$-octabromo-mesotriarylcorroles, the gold undecaarylcorrole was found to be moderately soluble in organic solvents. The relatively high solubility appears to be related to the lack of intermolecular aurophilic and metallophilic interactions involving the gold atom.

\section{Experimental section}

Materials. All reagents and solvents were used as purchased unless stated otherwise. Anhydrous toluene (Sigma-aldrich) was stored over pre-activated 3 A molecular sieves. Silica gel 150 (35-70 $\mu \mathrm{m}$ particle size, Davisil) was used for flash chromatography and silica gel 60 plates $(20 \times 20 \mathrm{~cm}$; $0.5 \mathrm{~mm}$ thick, Merck) were used for preparative thin-layer chromatography (PLC). Copper $\beta$ octabromo-meso-tris(4-methylphenyl)corrole, $\mathrm{Cu}\left[\mathrm{Br}_{8} \mathrm{Me}_{3}\right]$ and copper $\beta$-octabromo-mesotriphenylcorrole, $\mathrm{Cu}\left[\mathrm{Br}_{8} \mathrm{H}_{3}\right]$, served as the starting materials for copper undecaarylcorroles and were synthesized as previously described. ${ }^{[37]}$ Copper $\beta$-octakis( $p$-trifluoromethylphenyl)-mesotriphenylcorrole], $\mathrm{Cu}\left[\left(\mathrm{CF}_{3}\right)_{8} \mathrm{H}_{3}\right]$, was also synthesized according to a literature method. ${ }^{[15]}$

Instrumentation. Ultraviolet-visible (UV-vis) spectra were recorded with $\mathrm{CH}_{2} \mathrm{Cl}_{2}$ as solvent on an HP 8453 spectrophotometer. ${ }^{1} \mathrm{H}$ NMR spectra were obtained at $298 \mathrm{~K}$ on either a Mercury Plus Varian spectrometer (400 MHz) in $\mathrm{CDCl}_{3}$ (referenced to $7.26 \mathrm{ppm}$ ), in $\mathrm{CD}_{2} \mathrm{Cl}_{2}$ (referenced to $5.30 \mathrm{ppm}$ ), and in $\mathrm{C}_{6} \mathrm{D}_{6}$ (referenced to $7.20 \mathrm{ppm}$ ) or a Varian Inova spectrometer $(600 \mathrm{MHz})$ equipped with a cryogenically cooled inverse triple-resonance probe in 1,1,2,2tetrachloroethane- $d_{2}\left(\mathrm{CDCl}_{2}-\mathrm{CDCl}_{2}\right.$, referenced to 5.91ppm). ${ }^{19} \mathrm{~F}$ NMR spectra (376 $\left.\mathrm{MHz}\right)$ were recorded at 298-333K on a Mercury Plus Varian spectrometer and referenced to 2,2,2trifluoroethanol- $d_{3}(\delta=-77.8 \mathrm{ppm})$. Electrospray ionization mass spectra were recorded on an LTQ Orbitrap XL spectrometer. 
General Procedure for the Synthesis of Copper Undecaarylcorroles. The syntheses were carried essentially according to the procedure reported by Ghosh and coworkers. ${ }^{[15]}$ Into a 50-mL three-necked round-bottomed flask equipped with a magnetic stirring bar and a reflux condenser were introduced $\mathrm{Cu}\left[\mathrm{Br}_{8} \mathrm{Me}_{3}\right]$, the arylboronic acid of choice (40 equiv), potassium carbonate (40 equiv), and $\mathrm{Pd}_{2}\left(\mathrm{dba}_{3} \cdot \mathrm{CHCl}_{3}(0.1\right.$ equiv). After degassing with argon, dry toluene $(10 \mathrm{~mL})$ was added. After purging with argon for $10 \mathrm{~min}$, the suspension was stirred at 100-105 ${ }^{\circ} \mathrm{C}$ under argon for 1-2 days. Progress of the reaction was monitored by mass spectrometry. When product formation appeared to have stabilized, the reaction mixture was cooled to room temperature, diluted with $10 \mathrm{~mL}$ of $\mathrm{CH}_{2} \mathrm{Cl}_{2}$, and washed with saturated aqueous $\mathrm{NaHCO}_{3}$ and then with distilled water. The $\mathrm{CH}_{2} \mathrm{Cl}_{2}$ phase was dried with anhydrous $\mathrm{Na}_{2} \mathrm{SO}_{4}$, filtered, and evaporated. The brown residue obtained was chromatographed on a silica gel column with hexane $/ \mathrm{CH}_{2} \mathrm{Cl}_{2}$ as eluent. The product eluted as a dark brown band, which was collected and evaporated to dryness. The residue was purified by preparative thin-layer chromatography (PLC), as detailed below for each corrole.

\section{Synthesis of Copper 2,3,7,8,12,13,17,18-octakis(4-fluorophenyl)-meso-tris(p-} methylphenyl)corrole, $\mathbf{C u}\left[\mathbf{F}_{8} \mathbf{M e}_{3}\right]$. The reaction employed $0.025 \mathrm{~mol}(32 \mathrm{mg})$ of $\mathrm{Cu}\left[\mathrm{Br}_{8} \mathrm{TMePC}\right]$ and was complete after $\sim 2$ days $(45 \mathrm{~h})$. Both the column chromatography and subsequent PLC were carried out with 3:1 hexane/ $\mathrm{CH}_{2} \mathrm{Cl}_{2}$ as eluent. The pure product $\mathrm{Cu}\left[\mathrm{F}_{8} \mathrm{Me}_{3}\right]$ (26.6 $\mathrm{mg}, 76 \%)$ eluted as the most intense brown band. UV-vis $\left(\mathrm{CH}_{2} \mathrm{Cl}_{2}\right): \lambda_{\max }, \mathrm{nm}\left(\varepsilon \times 10^{-4}, \mathrm{M}^{-1}\right.$ $\left.\mathrm{cm}^{-1}\right): 448$ (3.56), 644 (0.32). ${ }^{1} \mathrm{H}$ NMR $\left(\mathrm{CDCl}_{3}, 400 \mathrm{MHz}, \delta\right.$ in ppm): $\delta 6.87(\mathrm{~d}, J=8.0 \mathrm{~Hz}, 2 \mathrm{H}, 10-$ $o$, 4- $\mathrm{CH}_{3} \mathrm{Ph}$ ), 6.80-6.74 (m, 4H, 2,18-o, 4-FPh; 4H, 5,15-o, 4- $\mathrm{CH}_{3} \mathrm{Ph}$ ), 6.57-6.51 (m, 4H, 3, 17-o, 4-FPh; 4H, 2,18-m, 4-FPh), 6.47-6.26 (m, 4H, 8,12-o, 4-FPh; 4H, 7,13-o, 4-FPh; 4H, 3,17-m, 4$\mathrm{FPh}$; 4H, 5,15-m, 4- $\mathrm{CH}_{3} \mathrm{Ph}$; 4H, 7,13-m, 4-FPh; 4H, 8,12-m, 4-FPh; 2H, 10-m, 4- $\mathrm{CH}_{3} \mathrm{Ph}$ ), 2.02 (s, $\left.6 \mathrm{H}, 5,15-p, 4-\mathrm{CH}_{3} \mathrm{Ph}\right), 1.91$ (s, 3H, 10-p, 4- $\left.\mathrm{CH}_{3} \mathrm{Ph}\right) .{ }^{19} \mathrm{~F} \mathrm{NMR}\left(\mathrm{CDCl}_{3}\right): \delta-116.31$ to $-116.39(\mathrm{~m}$, $2 \mathrm{~F}),-118.08$ to $-118.21(\mathrm{~m}, 4 \mathrm{~F}),-118.62$ to $-118.70(\mathrm{~m}, 2 \mathrm{~F})$. MS (HR-ESI, major isotopomer): $[\mathrm{M}]^{+}=1380.3440$ (expt), 1380.3438 (calcd).

\section{Synthesis of Copper 2,3,7,8,12,13,17,18-Octakis(4-trifluoromethylphenyl)-5,10,15-} tris(4-methylphenyl)corrole, $\mathbf{C u}\left[\left(\mathbf{C F}_{3}\right)_{\mathbf{8}} \mathbf{M e}_{3}\right]$. The reaction employed $0.020 \mathrm{~mol}(25 \mathrm{mg})$ of $\mathrm{Cu}\left[\mathrm{Br}_{8} \mathrm{TMePC}\right]$ and was complete after $24 \mathrm{~h}$. Both the column chromatography and subsequent PLC were carried out with 3:1 hexane/ $\mathrm{CH}_{2} \mathrm{Cl}_{2}$ as eluent. The pure product $\mathrm{Cu}\left[\left(\mathrm{CF}_{3}\right)_{8} \mathrm{Me}_{3}\right](18.4$ $\mathrm{mg}, 52 \%)$ eluted as the most intense brown band. UV-vis $\left(\mathrm{CH}_{2} \mathrm{Cl}_{2}\right): \lambda_{\max }, \mathrm{nm}\left(\varepsilon \times 10^{-4}, \mathrm{M}^{-1} \mathrm{~cm}^{-1}\right)$ : 454 (4.34), 642 (0.44), 841 (0.59). ${ }^{1} \mathrm{H}$ NMR ( $\mathrm{CDCl}_{3}, 600 \mathrm{MHz}, \delta$ in ppm): $\delta 7.09$ (d, $J=4.0 \mathrm{~Hz}$, 
4H, 2,18-o, 4-CF $3 \mathrm{Ph}$ ), 6.97 (d, J=4.0 Hz, 4H, 2,18-m, 4-CF 3 Ph), 6.94 (d, J=4.0 Hz, 4H, 3,17-o, 4$\left.\mathrm{CF}_{3} \mathrm{Ph}\right), 6.89$ (d, J=4.0 Hz, 4H, 7,13-o, 4- $\left.\mathrm{CF}_{3} \mathrm{Ph}\right), 6.85$ (d, J=4.0 Hz, 4H, 8, 12-o, 4-CF $\left.\mathrm{Ph}\right), 6.81$ (d, J=8.0 Hz, 2H, 10- $\left.o, 4-\mathrm{CH}_{3} \mathrm{Ph}\right), 6.75$ (d, J=4.0 Hz, 4H, 3,17-m, 4-CF $\left.3 \mathrm{Ph}\right), 6.69$ (d, J=8.0 Hz, $\left.4 \mathrm{H}, 5,15-o, 4-\mathrm{CH}_{3} \mathrm{Ph}\right), 6.62$ (d, J=8.0 Hz, 8H, 7,8,12,13-m, 4- $\left.\mathrm{CF}_{3} \mathrm{Ph}\right), 6.25$ (d, J=4.0 Hz, 4H, 5, 15$m, 4-\mathrm{CH}_{3} \mathrm{Ph}$ ), 6.19 (d, J=8.0 Hz, 2H, 10-m, 4- $\left.\mathrm{CH}_{3} \mathrm{Ph}\right), 1.93$ (s, 6H, 5,15-p, 4- $\left.\mathrm{CH}_{3} \mathrm{Ph}\right), 1.82$ (s, 3H, 10-p, 4-CH3 $\mathrm{Ph}) .{ }^{19} \mathrm{~F}$ NMR $\left(\mathrm{CDCl}_{3}\right): \delta-63.07$ (s, 6F), -63.17 (s, 6F), -63.29 (s, 6F), -63.46 (s, 6F). MS (HR-ESI, major isotopomer): $[\mathrm{M}]^{+}=1781.3211$ (expt), 1781.3261 (calcd).

\section{Synthesis of Copper 2,3,7,8,12,13,17,18-octaphenyl-5,10,15-tris(4-}

methylphenyl)corrole, $\mathbf{C u}\left[\mathbf{H}_{\mathbf{8}} \mathbf{M e}_{3}\right]$. The reaction employed $0.021 \mathrm{~mol}(27 \mathrm{mg})$ of

$\mathrm{Cu}\left[\mathrm{Br}_{8} \mathrm{TMePC}\right]$ and was complete after $48 \mathrm{~h}$. Column chromatography was carried out with hexane $/ \mathrm{CH}_{2} \mathrm{Cl}_{2}$ as eluent, while 3:1 n-hexane/ $\mathrm{CH}_{2} \mathrm{Cl}_{2}$ was used for the PLC. The pure product $\mathrm{Cu}\left[\mathrm{H}_{8} \mathrm{Me}_{3}\right](12.1 \mathrm{mg}, 46 \%)$ eluted as the most intense brown band. $\mathrm{UV}$-vis $\left(\mathrm{CH}_{2} \mathrm{Cl}_{2}\right): \lambda_{\max }, \mathrm{nm}(\varepsilon$ x $\left.10^{-4}, \mathrm{M}^{-1} \mathrm{~cm}^{-1}\right): 448$ (6.17), 544 (0.77), 645 (0.49). ${ }^{1} \mathrm{H}$ NMR $\left(\mathrm{CD}_{2} \mathrm{Cl}_{2}, 600 \mathrm{MHz}, \delta\right.$ in ppm): $\delta$ 6.86 (d, J=8.4 Hz, 2H, 10-, $\left.4-\mathrm{CH}_{3} \mathrm{Ph}\right), 6.85-6.82$ (m, 4H, 2,18-, $\mathrm{Ph} ; 2 \mathrm{H}, 2,18-p, \mathrm{Ph}$ ), 6.80-6.76 (m, 4H, 2,18-m, Ph), 6.74 (d, J=7.8 Hz, 4H, 5,15-o, 4- $\left.\mathrm{CH}_{3} \mathrm{Ph}\right), 6.72-6.68$ (m, 2H, 3,17-p, Ph), 6.65-6.63 (m, 4H, 3,17-o, Ph; 4H, 3,17-m, Ph), 6.62-6.58 (m, 2H, 7,13-p, Ph; 4H, 7,13-m, Ph), 6.58-6.57 (m, 2H, 8,12-p, Ph), 6.57-6.54 (m, 4H, 8,12-m, Ph; 4H, 8,12-o, Ph), 6.54-6.52 (m, 4H, 7,13-o, Ph), 6.19 (d, J=7.2 Hz, 4H, 5,15-m, 4- $\left.\mathrm{CH}_{3} \mathrm{Ph}\right), 6.16$ (d, J=7.8 Hz, 2H, 10-m, 4-CH $\mathrm{CH}_{3}$, 1.90 (s, 6H, 5,15-p, 4- $\left.\mathrm{CH}_{3} \mathrm{Ph}\right), 1.80$ (s, 3H, 10-p, 4- $\mathrm{CH}_{3} \mathrm{Ph}$ ). MS (HR-ESI, major isotopomer): $[\mathrm{M}]^{+}=1237.4223(\mathrm{expt}), 1237.4220$ (calcd).

Undecaarylisocorrole $\mathbf{H}_{2}\left[\mathbf{F}_{8} \mathbf{M e}_{3}(\mathbf{5 - O H})\right]$. Into a $50 \mathrm{~mL}$ round-bottomed flask was placed $25 \mathrm{mg}(0.018 \mathrm{mmol})$ of $\mathrm{Cu}\left[\mathrm{F}_{8} \mathrm{Me}_{3}\right]$ and dissolved in $3 \mathrm{~mL}$ of $\mathrm{CH}_{2} \mathrm{Cl}_{2}$. Subsequently, $3 \mathrm{~mL}$ of concentrated $\mathrm{H}_{2} \mathrm{SO}_{4}(95-97 \%$, Merck) was added. The mixture was then stirred and sonicated at room temperature. Progress of the reaction was monitored by ESI mass spectrometry. After $2 \mathrm{~h}$, the reaction mixture was carefully poured into $300 \mathrm{~mL}$ of distilled $\mathrm{H}_{2} \mathrm{O}$ and then extracted with $\mathrm{CHCl}_{3}$. The organic phase was washed once with distilled water and twice with saturated aqueous $\mathrm{NaHCO}_{3}$. Upon washing with $\mathrm{NaHCO}_{3}$, the color of the organic phase changed from brown to green. The organic phase was then dried with anhydrous $\mathrm{Na}_{2} \mathrm{SO}_{4}$, filtered, and the filtrate rotaryevaporated to dryness. The residue obtained was chromatographed on a silica gel column with $\mathrm{CH}_{2} \mathrm{Cl}_{2} / 1 \%-\mathrm{MeOH}$. The product was further purified by PLC with 2:3n-hexane/ $\mathrm{CH}_{2} \mathrm{Cl}_{2}$; upon completion of the PLC, the pure product $\mathrm{H}_{2}\left[\mathrm{~F}_{8} \mathrm{Me}_{3}(5-\mathrm{OH})\right](14.4 \mathrm{mg}, 60 \%)$ was obtained as the most intense green band in the middle of the plate. UV-vis $\left(\mathrm{CH}_{2} \mathrm{Cl}_{2}\right): \lambda_{\max }, \mathrm{nm}\left(\varepsilon \times 10^{-4}, \mathrm{M}^{-1} \mathrm{~cm}^{-}\right.$ 
$\left.{ }^{1}\right): 433$ (3.37), 683 (0.69). ${ }^{1} \mathrm{H}$ NMR $\left(\mathrm{C}_{6} \mathrm{D}_{6}, 600 \mathrm{MHz}, \delta\right.$ in ppm): $\delta 8.05$ (d, $J=8.1 \mathrm{~Hz}, 2 \mathrm{H}, 5-o, 4-$ $\left.\mathrm{CH}_{3} \mathrm{Ph}\right), 7.01(\mathrm{~d}, J=8.3 \mathrm{~Hz}, 2 \mathrm{H}, 5-m, 4-\mathrm{FPh}), 6.81\left(\mathrm{~d}, J=8.1 \mathrm{~Hz}, 1 \mathrm{H}, 10-o, 4-\mathrm{CH}_{3} \mathrm{Ph}\right), 6.80(\mathrm{~d}, J$ $=8.6 \mathrm{~Hz}, 2 \mathrm{H}, 3-o, 4-\mathrm{FPh}), 6.70(\mathrm{~d}, J=8.0 \mathrm{~Hz}, 1 \mathrm{H}, 7-o, 4-\mathrm{FPh}), 6.69$ (t, $J=7.6 \mathrm{~Hz}, 1 \mathrm{H}, 7-m, 4-$ FPh), 6,60 (d, $J=8.6 \mathrm{~Hz}, 2 \mathrm{H}, 2-o, 4-\mathrm{FPh}), 6.55$ (t, $J=8.5 \mathrm{~Hz}, 2 \mathrm{H}, 3-m, 4-\mathrm{FPh}), 6.44$ (overlapping, 1H, 7-o, 4-FPh), 6.42 (o, 12-o, 4-FPh), 6.36 (o, 1H, 7-m, 4-FPh), 6.33 (o, 1H, 10-m, 4- $\left.\mathrm{CH}_{3} \mathrm{Ph}\right), 6.29$ (o, 1H, 8-m, 4-FPh), 6.25 (t, $\left.J=8.8 \mathrm{~Hz}, 2 \mathrm{H}, 2-m, 4-\mathrm{FPh}\right), 6.20$ (o, 1H, 8- o, 4$\mathrm{FPh}$ ), 6.11 (o, 1H, 8-m, 4-FPh), 6.07 (d, J=8.4 Hz, 1H, 10-, $\left.4-\mathrm{CH}_{3} \mathrm{Ph}\right), 6.02$ (t, $J=8.5 \mathrm{~Hz}, 0.5 \mathrm{H}$, 12-m, 4-FPh), 5.65 (d, $J=7.8 \mathrm{~Hz}, 1 \mathrm{H}, 10-m, 4-\mathrm{CH}_{3} \mathrm{Ph}$ ), 2.29 (s, 1H, -OH), 2.05 (s, 3H, 5- $p$, 4$\mathrm{CH}_{3} \mathrm{Ph}$ ), 1.86 (s, 3H, 15-p, 4- $\left.\mathrm{CH}_{3} \mathrm{Ph}\right), 1.72$ (s, 3H, 10-p, 4- $\left.\mathrm{CH}_{3} \mathrm{Ph}\right) .{ }^{19} \mathrm{~F} \mathrm{NMR}\left(\mathrm{CDCl}_{3}\right): \delta-115.96$ to $-116.08(\mathrm{~m}, 1 \mathrm{~F}),-116.25$ to $-116.36(\mathrm{~m}, 1 \mathrm{~F}),-116.45$ to $-116.59(\mathrm{~m}, 1 \mathrm{~F}),-117.38$ to -117.49 (m, 1F), -117.79 to -117.88 (m, 1F), -117.95 to -118.09 (m, 2F), -118.25 to -118.35 (m, 1F). MS (HRESI, major isotopomer): $[\mathrm{M}+\mathrm{H}]^{+}=1337.4415$ (expt), 1337.4399 (calcd).

\section{Undecaarylisocorroles $\mathrm{H}_{2}\left[\left(\mathrm{CF}_{3}\right)_{8} \mathrm{Me}_{3}(5-\mathrm{OH})\right]$ and $\mathrm{H}_{2}\left[\left(\mathrm{CF}_{3}\right)_{8} \mathrm{Me}_{3}(\mathbf{1 0 - O H})\right]$. Into a 50}

$\mathrm{mL}$ round-bottomed flask, $20 \mathrm{mg}(0.0112 \mathrm{mmol})$ of $\mathrm{Cu}\left[\left(\mathrm{CF}_{3}\right)_{8} \mathrm{Me}_{3}\right]$ was added and dissolved in 4 mL of $\mathrm{CH}_{2} \mathrm{Cl}_{2}$. Subsequently, $2 \mathrm{~mL}$ of concentrated $\mathrm{H}_{2} \mathrm{SO}_{4}$ (95-97\%, Merck) was added. The mixture was stirred and sonicated at room temperature. The progress of the reaction was monitored by ESI mass spectrometry. After 4 hours the reaction was quenched by pouring the mixture into $300 \mathrm{~mL}$ distilled $\mathrm{H}_{2} \mathrm{O}$ and then extracted with $\mathrm{CHCl}_{3}$. The brown organic phase was washed once with distilled water and once with saturated aqueous $\mathrm{NaHCO}_{3}$. Upon washing with $\mathrm{NaHCO}_{3}$ the color of organic phase changed from brown to green. The organic phase was dried with anhydrous $\mathrm{Na}_{2} \mathrm{SO}_{4}$, filtered and evaporated under vacuum. The residue obtained was chromatographed on a silica gel column with $2: 1 n$-hexane/ $\mathrm{CH}_{2} \mathrm{Cl}_{2}$. The product was further purified by PLC with 2:1 n-hexane/ $\mathrm{CH}_{2} \mathrm{Cl}_{2}$. The most intense green band in the middle of the plate was pure $\mathrm{H}_{2}\left[\left(\mathrm{CF}_{3}\right)_{8} \mathrm{Me}_{3}(5-\mathrm{OH})\right](11 \mathrm{mg}, 57 \%)$ and the most intense light-green band below that was $\mathrm{H}_{2}\left[\left(\mathrm{CF}_{3}\right)_{8} \mathrm{Me}_{3}(10-\mathrm{OH})\right](3.7 \mathrm{mg}, 19 \%)$. X-ray quality crystals of $\mathrm{H}_{2}\left[\left(\mathrm{CF}_{3}\right)_{8} \mathrm{Me}_{3}(5-\mathrm{OH})\right]$ were grown by slow diffusion of $n$-heptane into the benzene solution. Analytical data for the two isomers are as follows.

Undecaarylisocorrole $\mathrm{H}_{2}\left[\left(\mathrm{CF}_{3}\right)_{8} \mathrm{Me}_{3}(5-\mathrm{OH})\right]$. UV-vis $\left(\mathrm{CH}_{2} \mathrm{Cl}_{2}\right): \lambda_{\max }, \mathrm{nm}\left(\varepsilon \times 10^{-4}, \mathrm{M}^{-1}\right.$ $\left.\mathrm{cm}^{-1}\right): 435$ (4.19), 683 (0.92). ${ }^{1} \mathrm{H}$ NMR $\left(\mathrm{C}_{6} \mathrm{D}_{6}, 600 \mathrm{MHz}, \delta\right.$ in ppm): $\delta 7.95$ (d, $J=8.0 \mathrm{~Hz}, 2 \mathrm{H}, 5-o$, 4- $\left.\mathrm{CH}_{3} \mathrm{Ph}\right), 7.22$ (d, $\left.J=8.0 \mathrm{~Hz}, 1 \mathrm{H}, 7-m, 4-\mathrm{CF}_{3} \mathrm{Ph}\right), 7.05$ (d, $\left.J=8.0 \mathrm{~Hz}, 2 \mathrm{H}, 3-m, 4-\mathrm{CF}_{3} \mathrm{Ph}\right), 7.03$ $\left(\mathrm{d}, J=8.1 \mathrm{~Hz}, 2 \mathrm{H}, 5-m, 4-\mathrm{CH}_{3} \mathrm{Ph}\right), 6.87\left(\mathrm{~d}, J=7.9 \mathrm{~Hz}, 2 \mathrm{H}, 3-o, 4-\mathrm{CF}_{3} \mathrm{Ph}\right), 6.75(\mathrm{~d}, J=8.4 \mathrm{~Hz}$, $\left.1 \mathrm{H}, 7-m, 4-\mathrm{CF}_{3} \mathrm{Ph}\right), 6.72\left(\mathrm{~d}, J=8.0 \mathrm{~Hz}, 1 \mathrm{H}, 7-o, 4-\mathrm{CF}_{3} \mathrm{Ph}\right), 6.68\left(\mathrm{o}, 1 \mathrm{H}, 10-o, 4-\mathrm{CH}_{3} \mathrm{Ph}\right), 6.61$ (d, 
$\left.J=8.6 \mathrm{~Hz}, 1 \mathrm{H}, 8-m, 4-\mathrm{CF}_{3} \mathrm{Ph}\right), 6.61$ (o, 2H, 12-m, 4- $\left.\mathrm{CF}_{3} \mathrm{Ph}\right), 6.61$ (o, 1H, 15-m, 4-CH $\left.\mathrm{CH}_{3} \mathrm{Ph}\right), 6.6$ (o, $\left.2 \mathrm{H}, 2-m, 4-\mathrm{CF}_{3} \mathrm{Ph}\right), 6.6$ (o, 2H, 2-o, 4- $\left.\mathrm{CF}_{3} \mathrm{Ph}\right), 6.57$ (o, 1H, 15-m, 4- $\left.\mathrm{CH}_{3} \mathrm{Ph}\right), 6.53$ (d, J = 8.2 Hz, $1 \mathrm{H}, 8-m, 4-\mathrm{CF}_{3} \mathrm{Ph}$ ), 6.44 (d, $J=8.4 \mathrm{~Hz}, 1 \mathrm{H}, 7-o, 4-\mathrm{CF}_{3} \mathrm{Ph}$ ), 6.37 (broad, 1H, 15-o, 4-CH $\mathrm{CH}_{3} \mathrm{Ph}, 6.35$ $\left(\mathrm{d}, J=8.6 \mathrm{~Hz}, 1 \mathrm{H}, 8-o, 4-\mathrm{CF}_{3} \mathrm{Ph}\right), 6.26$ (b, 1H, 15-o, 4- $\left.\mathrm{CH}_{3} \mathrm{Ph}\right), 6.17$ (d, J = 7.9 Hz, 1H, 10-m, 4$\left.\mathrm{CH}_{3} \mathrm{Ph}\right), 6.13\left(\mathrm{~d}, J=8.2 \mathrm{~Hz}, 1 \mathrm{H}, 8-o, 4-\mathrm{CF}_{3} \mathrm{Ph}\right), 5.93\left(\mathrm{~d}, J=7.8 \mathrm{~Hz}, 1 \mathrm{H}, 10-o, 4-\mathrm{CH}_{3} \mathrm{Ph}\right), 5.48$ (d, $\left.J=7.8 \mathrm{~Hz}, 1 \mathrm{H}, 10-m, 4-\mathrm{CH}_{3} \mathrm{Ph}\right), 2.07$ (s, 3H, 5-p, 4- $\left.\mathrm{CH}_{3} \mathrm{Ph}\right), 1.97$ (s, 1H, -OH), 1.86 (s, 3H, 15-p, 4-CH $\left.3{ }_{3} \mathrm{Ph}\right), 1.68$ (s, 3H, 10-p, 4- $\left.\mathrm{CH}_{3} \mathrm{Ph}\right) .{ }^{19} \mathrm{~F} \mathrm{NMR}\left(\mathrm{C}_{6} \mathrm{D}_{6}, 60^{\circ} \mathrm{C}\right): \delta-62.58(\mathrm{~s}, 3 \mathrm{~F}),-62.72(\mathrm{~s}, 9 \mathrm{~F}),-$ $62.88(\mathrm{~s}, 3 \mathrm{~F}),-62.95(\mathrm{~s}, 3 \mathrm{~F}),-63.06(\mathrm{~s}, 3 \mathrm{~F}),-63.32$ (s, 3F). MS (HR-ESI, major isotopomer): [M + $\mathrm{H}]^{+}=1738.4250$ (expt), 1738.4177 (calcd).

Undecaarylisocorrole $\mathbf{H}_{2}\left[\left(\mathbf{C F}_{3}\right)_{8} \mathbf{M e}_{3}(\mathbf{1 0 - O H})\right]$. UV-vis $\left(\mathrm{CH}_{2} \mathrm{Cl}_{2}\right): \lambda_{\max }, \mathrm{nm}\left(\varepsilon \times 10^{-4}, \mathrm{M}^{-1}\right.$ $\left.\mathrm{cm}^{-1}\right): 458$ (1.86), 658 (0.26). ${ }^{1} \mathrm{H}$ NMR $\left(\mathrm{C}_{6} \mathrm{D}_{6}, 600 \mathrm{MHz}, \delta\right.$ in ppm): $\delta 7.46(\mathrm{~d}, J=8.3 \mathrm{~Hz}, 2 \mathrm{H}, 10$ $\left.o, 4-\mathrm{CH}_{3} \mathrm{Ph}\right), 6.95$ (d, $\left.J=8.1 \mathrm{~Hz}, 4 \mathrm{H}, 12-m, 4-\mathrm{CF}_{3} \mathrm{Ph}\right), 6.80$ (d, $\left.J=8.2 \mathrm{~Hz}, 4 \mathrm{H}, 18-m, 4-\mathrm{CF}_{3} \mathrm{Ph}\right)$, $6.77\left(\mathrm{~d}, J=8.1 \mathrm{~Hz}, 2 \mathrm{H}, 10-m, 4-\mathrm{CH}_{3} \mathrm{Ph}\right), 6.72\left(\mathrm{~d}, J=8.3 \mathrm{~Hz}, 4 \mathrm{H}, 18-o, 4-\mathrm{CF}_{3} \mathrm{Ph}\right), 6.68(\mathrm{~d}, J=8.0$ $\left.\mathrm{Hz}, 4 \mathrm{H}, 17-m, 4-\mathrm{CF}_{3} \mathrm{Ph}\right), 6.68$ (b, 12-o, 4- $\left.\mathrm{CF}_{3} \mathrm{Ph}\right), 6.62$ (d, $\left.J=8.0 \mathrm{~Hz}, 4 \mathrm{H}, 13-m, 4-\mathrm{CF}_{3} \mathrm{Ph}\right), 6.40$ $\left(\mathrm{d}, J=7.9 \mathrm{~Hz}, 4 \mathrm{H}, 17-o, 4-\mathrm{CF}_{3} \mathrm{Ph}\right), 6.30\left(\mathrm{~d}, J=8.0 \mathrm{~Hz}, 4 \mathrm{H}, 13-o, 4-\mathrm{CF}_{3} \mathrm{Ph}\right), 6.28(\mathrm{~d}, J=7.9 \mathrm{~Hz}$, $\left.4 \mathrm{H}, 15-o, 4-\mathrm{CH}_{3} \mathrm{Ph}\right), 5.86$ (d, J = 7.8 Hz, 4H, 15-m, 4- $\left.\mathrm{CH}_{3} \mathrm{Ph}\right), 2.39$ (s, 1H, -OH), 1.98 (s, 3H, 10$\left.p, 4-\mathrm{CH}_{3} \mathrm{Ph}\right), 1.80$ (s, 6H, 5,15-p, 4- $\left.\mathrm{CH}_{3} \mathrm{Ph}\right) .{ }^{19} \mathrm{~F} \mathrm{NMR}\left(\mathrm{CDCl}_{3}\right): \delta-63.06(\mathrm{~s}, 6 \mathrm{~F}),-63.15(\mathrm{~s}, 6 \mathrm{~F}),-$ 63.19 (s, 6F), -63.54 (s, 6F). MS (HR-ESI, major isotopomer): $[\mathrm{M}+\mathrm{H}]^{+}=1738.4135$ (expt), 1738.4177 (calcd).

\section{Single-crystal X-ray diffraction analysis of Undecaarylisocorrole $\mathrm{H}_{2}\left[\left(\mathrm{CF}_{3}\right)_{8} \mathrm{Me}_{3}(5-\right.$} OH)]. X-ray data for $\mathrm{H}_{2}\left[\left(\mathrm{CF}_{3}\right)_{8} \mathrm{Me}_{3}(5-\mathrm{OH})\right]$ were collected on beamline 11.3.1 at the Advanced Light Source, Lawrence Berkeley National Laboratory. Samples were mounted on MiTeGen ${ }^{\circledR}$ kapton loops and placed in a 100(2) K nitrogen cold stream provided by an Oxford Cryostream 700 Plus low temperature apparatus on the goniometer head of a Bruker D8 diffractometer equipped with a APEX-II CCD detector. Diffraction data were collected with synchrotron radiation monochromated using silicon(111) to a wavelength of $0.7749(1) \AA$. An approximate fullsphere of data was collected using a $\omega$ scans with scan rates of 3 seconds per 0.5 degree with $2 \theta=$ $-36^{\circ}$. The structures were solved by intrinsic phasing (SHELXT) and refined by full-matrix least squares on $F^{2}$ (SHELXL-2014). All non-hydrogen atoms were refined anisotropically. Hydrogen atoms were geometrically calculated and refined as riding atoms. The hydrogen atoms on the nitrogen and oxygen atoms were found in the Fourier difference map and allowed to ride on their respective $\mathrm{N}$ or $\mathrm{O}$ atoms. Additional crystallographic information has been summarized in Table 
1 and full details can be found in the crystallographic information file provided in the Supplementary Information.

Undecaarylisocorrole $\mathbf{H}_{2}\left[\mathbf{H}_{8} \mathbf{M e}_{3}(\mathbf{5}-\mathbf{O H})\right]$. Into a $50 \mathrm{~mL}$ round-bottomed flask, $12 \mathrm{mg}$ $(0.0097 \mathrm{mmol})$ of $\mathrm{Cu}\left[\mathrm{H}_{8} \mathrm{Me}_{3}\right]$ was added and dissolved in $2 \mathrm{~mL}$ of $\mathrm{CH}_{2} \mathrm{Cl}_{2}$. Subsequently, $2 \mathrm{~mL}$ of concentrated $\mathrm{H}_{2} \mathrm{SO}_{4}(95-97 \%$, Merck) was added. The mixture was stirred and sonicated at room temperature. The progress of the reaction was monitored by ESI mass spectrometry. After 2 hours the reaction was quenched by pouring the mixture into $300 \mathrm{~mL}$ distilled $\mathrm{H}_{2} \mathrm{O}$ and then extracted with $\mathrm{CHCl}_{3}$. The brown organic phase was washed once with distilled water and once with saturated aqueous $\mathrm{NaHCO}_{3}$. Upon washing with $\mathrm{NaHCO}_{3}$ the color of organic phase changed from brown to green. The organic phase was dried with anhydrous $\mathrm{Na}_{2} \mathrm{SO}_{4}$, filtered and evaporated under vacuum. The residue obtained was chromatographed on a silica gel column with $\mathrm{CH}_{2} \mathrm{Cl}_{2} / 5 \%-\mathrm{MeOH}$. The product was further purified by PLC with 1:2 n-hexane/ $\mathrm{CH}_{2} \mathrm{Cl}_{2}$. The olive-green band at the bottom of the plate was pure $\mathrm{H}_{2}\left[\mathrm{H}_{8} \mathrm{Me}_{3}(5-\mathrm{OH})\right]$. Yield: $5.6 \mathrm{mg}$, 48\%. UVvis $\left(\mathrm{CH}_{2} \mathrm{Cl}_{2}\right): \lambda_{\max }, \mathrm{nm}\left(\varepsilon \times 10^{-4}, \mathrm{M}^{-1} \mathrm{~cm}^{-1}\right): 439(0.69), 689(0.15) .{ }^{1} \mathrm{H} \mathrm{NMR}\left(\mathrm{C}_{6} \mathrm{D}_{6}, 600 \mathrm{MHz}, \delta\right.$ in ppm): $\delta 8.22$ (d, $\left.J=7.8 \mathrm{~Hz}, 2 \mathrm{H}, 5-o, 4-\mathrm{CH}_{3} \mathrm{Ph}\right), 7.07$ (d, $\left.J=7.2 \mathrm{~Hz}, 2 \mathrm{H}, 3-o, \mathrm{Ph}\right), 7.04$ (d, $J=8.1$ $\left.\mathrm{Hz}, 2 \mathrm{H}, 5-m, 4-\mathrm{CH}_{3} \mathrm{Ph}\right), 7.03$ (o, 7-o, $\left.\mathrm{Ph}\right), 7.0$ (b, 1H, 10-o, 4- $\left.\mathrm{CH}_{3} \mathrm{Ph}\right), 6.94$ (d, J = 7.2 Hz, 2H, 2$o, \mathrm{Ph}), 6.94$ (o, 7-p, Ph), 6.86 (t, J=7.5 Hz, 2H, 3-m, Ph), 6.81 (d, J=7.2 Hz, 1H, 3-p, Ph), 6.77 (o, 7-m, Ph), 6.73 (o, 7-m, Ph), 6.66 (o, 7-o, Ph), 6.56 (t, J = 6.8 Hz, 2H, 2-m, Ph), 6.56 (o, 15-o, 4- $\mathrm{CH}_{3} \mathrm{Ph}$ ), 6.55 (o, 8-m, Ph), 6.51 (12-m, Ph), 6.48 (o, 15-m, 4- $\mathrm{CH}_{3} \mathrm{Ph}$ ), 6.43 (o, 8-m, Ph), 6.37 (b, $\left.1 \mathrm{H}, 10-m, 4-\mathrm{CH}_{3} \mathrm{Ph}\right), 6.23$ (b, 1H, 10-o, 4- $\left.\mathrm{CH}_{3} \mathrm{Ph}\right), 5.56$ (b, 1H, 10-m, 4- $\left.\mathrm{CH}_{3} \mathrm{Ph}\right), 2.52$ (s, 1H, $\mathrm{OH}), 2.08$ (s, 3H, 5- $\left.p, 4-\mathrm{CH}_{3} \mathrm{Ph}\right), 1.82$ (s, 3H, 15- $\left.p, 4-\mathrm{CH}_{3} \mathrm{Ph}\right), 1.68$ (s, 3H, 10- $\left.p, 4-\mathrm{CH}_{3} \mathrm{Ph}\right) . \mathrm{MS}$ (HR-ESI major isotopomer): $[\mathrm{M}+\mathrm{H}]^{+}=1193.5179$ (expt), 1193.5153 (calcd).

Undecaarylisocorrole $\mathbf{H}_{2}\left[\left(\mathrm{CF}_{3}\right)_{8} \mathbf{H}_{3}(5-\mathbf{O H})\right]$. To a solution of $\mathrm{Cu}\left[\left(\mathrm{CF}_{3}\right)_{8} \mathrm{H}_{3}\right](25 \mathrm{mg}$, $0.014 \mathrm{mmol})$ in $\mathrm{CH}_{2} \mathrm{Cl}_{2}(7.0 \mathrm{~mL})$ was added dropwise $1 \mathrm{~mL} \mathrm{H}_{2} \mathrm{SO}_{4}(95-97 \%)$ and the resulting suspension was stirred for $30 \mathrm{~min}$. The mixture was poured into cold, distilled water and extracted with $\mathrm{CH}_{2} \mathrm{Cl}_{2}$. The green organic phase was washed once with distilled $\mathrm{H}_{2} \mathrm{O}$ and once with saturated aqueous $\mathrm{NaHCO}_{3}$, dried with anhydrous $\mathrm{Na}_{2} \mathrm{SO}_{4}$, and filtered. After concentration to a minimum volume, the organic phase was chromatographed on a silica gel column with 1:1 hexane $/ \mathrm{CH}_{2} \mathrm{Cl}_{2}$, whereupon the isocorrole isomers eluted as a green band. PLC with 3:2 hexane $/ \mathrm{CH}_{2} \mathrm{Cl}_{2}$ yielded the 5-OH-isocorrole $(17 \mathrm{mg}, 0.01,71.6 \%)$ as the first intense green band. Free base $\mathrm{H}_{3}\left[\left(\mathrm{CF}_{3}\right)_{8} \mathrm{H}_{3}\right](1.8 \mathrm{mg}, 7 \%)$ followed as a second, thinner green band, closely followed by a third, bright green band containing the $10-\mathrm{OH}$-isocorrole $(2.5 \mathrm{mg}, 11 \%)$. The latter two 
products were not fully characterized because of the small quantities obtained so analytical data are only reported for the 5-OH isomer. UV-Vis $\left(\mathrm{CH}_{2} \mathrm{Cl}_{2}\right): \lambda_{\max }, \mathrm{nm}\left(\varepsilon \times 10^{-4}, \mathrm{M}^{-1} \mathrm{~cm}^{-1}\right): 433$ (4.30), 681 (0.98). ${ }^{1} \mathrm{H}$ NMR $\left(\mathrm{C}_{6} \mathrm{D}_{6}\right): \delta 8.0(\mathrm{~d}, 2 \mathrm{H}, 5-o, \mathrm{Ph}), 7.20\left(\mathrm{~m}, 1 \mathrm{H}, 7-m, 4-\mathrm{CF}_{3} \mathrm{Ph}\right), 7.15(\mathrm{t}, 2 \mathrm{H}, 5-m$, $\mathrm{Ph}) ; 7.05-7.0\left(\mathrm{~m}, 3 \mathrm{H}, 5-p, \mathrm{Ph}\right.$ and 3-m, 4-CF $3 \mathrm{Ph}$ ), $6.82\left(\mathrm{~d}, 2 \mathrm{H}, 3-o, 4-\mathrm{CF}_{3} \mathrm{Ph}\right), 6.75(\mathrm{~d}, 1 \mathrm{H}, 10-o$, $\mathrm{Ph})$, 6.75- $6.56\left\{\mathrm{~m}, 7-m\left(1 \mathrm{H}, 4-\mathrm{CF}_{3} \mathrm{Ph}\right), 2-o, m\left(4 \mathrm{H}, 4-\mathrm{CF}_{3} \mathrm{Ph}\right), 8-m\left(1 \mathrm{H}, 4-\mathrm{CF}_{3} \mathrm{Ph}\right), 7-o(1 \mathrm{H}, 4-\right.$ $\left.\left.\mathrm{CF}_{3} \mathrm{Ph}\right), 15-m(2 \mathrm{H}, \mathrm{Ph})\right\}, 6.54\left(\mathrm{~d}, 1 \mathrm{H}, 8-m, 4-\mathrm{CF}_{3} \mathrm{Ph}\right), 6.42\left(\mathrm{~d}, 1 \mathrm{H}, 7-o, 4-\mathrm{CF}_{3} \mathrm{Ph}\right), 6.40-6.25\{\mathrm{~m}$, 15- $\left.p(1 \mathrm{H}, \mathrm{Ph}), 10-m(1 \mathrm{H}, \mathrm{Ph}), 8-o\left(2 \mathrm{H}, 4-\mathrm{CF}_{3} \mathrm{Ph}\right), 15-o(2 \mathrm{H}, \mathrm{Ph})\right\}, 6.20(\mathrm{t}, 1 \mathrm{H}, 10-p, \mathrm{Ph}), 6.10(\mathrm{~d}$, $\left.1 \mathrm{H}, 8-o, 4-\mathrm{CF}_{3} \mathrm{Ph}\right), 6.0(\mathrm{~d}, 1 \mathrm{H}, 10-o, \mathrm{Ph}), 5.65(\mathrm{t}, 1 \mathrm{H}, 10-m, \mathrm{Ph}) .{ }^{19} \mathrm{~F} \mathrm{NMR}\left(\mathrm{C}_{6} \mathrm{D}_{6}\right)_{2}: \delta-62.88(\mathrm{~s}$, 3F), -63.02 (s, 3F), -63.41 to -63.46 (m, 3F), -63.48 (s, 6F), -63.53 (s, 3F), -63.61 (s, 3F), -63.71 to -63.76 (m, 3F). HRMS (ESI ${ }^{+}$, major isotopomer): $[\mathrm{M}+\mathrm{H}]^{+}=1696.3692$ (expt), 1696.3708 (calcd). Elemental analysis. Found (calcd) : C, 65.86 (65.88); H, 3.20 (2.97), N, 3.27 (3.30).

\section{Synthesis of gold $\beta$-octakis( $p$-trifluoromethylphenyl)-meso-triphenylcorrole,}

$\mathbf{A u}\left[\left(\mathbf{C F}_{3}\right)_{\mathbf{8}} \mathbf{H}_{3}\right]$. Gold(III) acetate (11 mg, 5 equiv) was added to a green solution of a mixture of the isomeric isocorroles $\mathrm{H}_{2}\left[\left(\mathrm{CF}_{3}\right)_{8} \mathrm{H}_{3}(5 / 10-\mathrm{OH})\right](15 \mathrm{mg}, 0.009 \mathrm{mmol})$ pyridine $(5.0 \mathrm{~mL})$. After overnight stirring, the resulting reddish-brown suspension was evaporated and the residue eluted through silica gel with 7:3 hexane/ $\mathrm{CH}_{2} \mathrm{Cl}_{2}$, yielding the gold undecaarylcorrole as the first red band (7 mg, 41.5\%). Vapour diffusion of hexane into a $\mathrm{CH}_{2} \mathrm{Cl}_{2}$ solution yielded tiny rectangular needles of $\mathrm{x}$-ray quality in approximately a month. UV-Vis $\left(\mathrm{CH}_{2} \mathrm{Cl}_{2}\right): \lambda_{\max }, \mathrm{nm}\left(\varepsilon \times 10^{-4}, \mathrm{M}^{-1} \mathrm{~cm}^{-1}\right)$ : 434 (6.08), 544 (0.58). 580 (2.0). ${ }^{1} \mathrm{H}$ NMR (600 MHz, $\left.\left(\mathrm{CDCl}_{2}\right)_{2}\right): \delta 7.29$ (d, $J=8.2 \mathrm{~Hz}, 4 \mathrm{H}, 2,18$ $\left.o, 4-\mathrm{CF}_{3} \mathrm{Ph}\right), 7.15$ (d, 4H, 5, 15-o, Ph), 7.09 (d, 2H, 10-o, Ph), 7.05 (d, J = 8.1 Hz, 4H, 3, 17-o, 4$\left.\mathrm{CF}_{3} \mathrm{Ph}\right), 7.02\left(\mathrm{~d}, J=8.1 \mathrm{~Hz}, 4 \mathrm{H}, 2,18-m, 4-\mathrm{CF}_{3} \mathrm{Ph}\right), 6.96\left(\mathrm{~d}, J=7.9 \mathrm{~Hz}, 4 \mathrm{H}, 3,17-m, 4-\mathrm{CF}_{3} \mathrm{Ph}\right)$, $6.93-6.89$ (m, 8H, 7, 8, 12,13-m, 4- $\left.\mathrm{CF}_{3} \mathrm{Ph}\right), 6.87$ (d, $\left.J=8.0 \mathrm{~Hz}, 4 \mathrm{H}, 7,13-o, 4-\mathrm{CF}_{3} \mathrm{Ph}\right), 6.82(\mathrm{~d}, J$ $\left.=7.9 \mathrm{~Hz}, 4 \mathrm{H}, 8,12-o, 4-\mathrm{CF}_{3} \mathrm{Ph}\right), 6.74(\mathrm{t}, J=7.7 \mathrm{~Hz}, 2 \mathrm{H}, 5,15-p, \mathrm{Ph}), 6.65(\mathrm{t}, J=7.6 \mathrm{~Hz}, 1 \mathrm{H}, 10-p$, $\mathrm{Ph}), 6.49(\mathrm{t}, J=7.7 \mathrm{~Hz}, 4 \mathrm{H}, 5,15-m, \mathrm{Ph}), 6.41(\mathrm{t}, J=7.7 \mathrm{~Hz}, 2 \mathrm{H}, 10-m, \mathrm{Ph}) .{ }^{19} \mathrm{~F} \mathrm{NMR}\left(\mathrm{CDCl}_{3}\right): \delta$

-63.31 (s, 12F); -63.42 (s, 6F); -63.49 (s, 6F). $\mathrm{HRMS}_{\text {(ESI }}^{+}$, major isotopomer): $[\mathrm{M}]^{+}=1873.3112$ (expt), 1873.3110 (calcd). Elemental analysis. Found (calcd) : C, 59.90 (59.63); H, 2.77 (2.53), N, 3.11 (2.99).

\section{Single-crystal X-ray diffraction analysis of the gold undecaarylcorrole $\mathrm{Au}\left[\left(\mathrm{CF}_{3}\right)_{8} \mathrm{H}_{3}\right]$.} $\mathrm{X}$-ray data for $\mathrm{Au}\left[\left(\mathrm{CF}_{3}\right)_{8} \mathrm{H}_{3}\right]$ were collected on beamline 11.3.1 at the Advanced Light Source, Lawrence Berkeley National Laboratory. A red tablet with dimensions 50 × 40 × $15 \mu \mathrm{m}^{3}$ was mounted on a MiTeGen ${ }^{\circledR}$ kapton loop and placed in a 100(2) K nitrogen cold stream provided by an Oxford Cryostream 700 Plus low temperature apparatus on the goniometer head of a Bruker 
D8 diffractometer equipped with a PHOTON100 CMOS detector operating in shutterless mode. Diffraction data were collected with synchrotron radiation monochromated using silicon(111) to a wavelength of $0.7749(1) \AA$. An approximate full-sphere of data was collected using a combination of $\phi$ and $\omega$ scans with scan speeds of 1 second per degree for the $\phi$ scans, and 1 and 3 seconds per degree for the $\omega$ scans at $2 \theta=0$ and $-45^{\circ}$, respectively. The structures were solved by intrinsic phasing (SHELXT) and refined by full-matrix least squares on $F^{2}$ (SHELXL-2014). All nonhydrogen atoms were refined anisotropically. Hydrogen atoms were geometrically calculated and refined as riding atoms. Additional crystallographic information has been summarized in Table 1 and full details can be found in the crystallographic information file provided in the Supporting Information.

Supporting information. UV-vis, ${ }^{1} \mathrm{H}$ NMR, and high-resolution mass spectra (42 pages); crystallographic information files for $\mathrm{H}_{2}\left[\left(\mathrm{CF}_{3}\right)_{8} \mathrm{Me}_{3}(5-\mathrm{OH})\right]$ and $\mathrm{Au}\left[\left(\mathrm{CF}_{3}\right)_{8} \mathrm{H}_{3}\right]$.

Acknowledgement. This work was supported by the of the Research Council of Norway (FRINATEK project 231086, AG) and the Advanced Light Source, Berkeley, California (CMB, KJG). The Advanced Light Source is supported by the Director, Office of Science, Office of Basic Energy Sciences, of the U.S. Department of Energy under Contract No. DE-AC02$05 \mathrm{CH} 11231$.

\section{References}

[1] For a review on applications of corroles, see: I. Aviv-Harel, Z. Gross, Chem. Eur. J. 15 (2009) 8382-8394.

[2] K. E. Thomas, A. B. Alemayehu, J. Conradie, C. M. Beavers, A. Ghosh, Acc. Chem. Res. 45 (2012) 1203-1214.

[3] J. H. Palmer, Struct. Bond. 142 (2012) 49-89.

[4] H. L. Buckley, J. Arnold, Dalton Trans. 44 (2015) 30-36.

[5] C. Capar, K. E. Thomas, A. Ghosh, J. Por. Phthalocya. 12 (2008) 964-967.

[6] F. Mandoj, S. Nardis, G. Pomarico, R. Paolesse, J. Por. Phthalocya. 12 (2008) 19-26.

[7] H. Y. Liu, L. Chen, F. Yam, H. Y. Zhan, X. Ying, X. L. Wang, H. F. Jiang, C. K. Chang, Chin. Chem. Lett. 19 (2008) 1000-1003.

[8] T. H. Ngo, W.Van Rossom, W. Dehaen, W. Maes, Org. Biomol. Chem. 7 (2009) 439-443.

[9] C. Capar, L.-K. Hansen, J. Conradie, A. Ghosh, J. Por. Phthalocya. 14 (2010) 509-512. 
[10] J. Capar, J. Conradie, C. M. Beavers, A. Ghosh, J. Phys. Chem. A 119 (2015) 3452-3457.

[11] J. Capar, S. Berg, K. E. Thomas, C. M. Beavers, K. J. Gagnon, A. Ghosh, J. Inorg. Biochem. 153 (2015) 162-166.

[12] A. Alemayehu, A. Ghosh, J. Por. Phthalocya. 15 (2011) 106-110.

[13] E. Rabinovitch, I. Goldberg, Z. Gross, Chem. Eur. J. 17 (2011) 12294-12301.

[14] A. M. Albrett, K. E. Thomas, S. Maslek, A. Młodzianowska, J. Conradie, C. M. Beavers, A. Ghosh, P. J. Brothers, Inorg. Chem. 53 (2014) 5486-5493.

[15] S. Berg, K. E. Thomas, C. M. Beavers, A. Ghosh, Inorg. Chem. 51, (2012) 9911-9916.

[16] D. Gao, G. Canard, M. Giorgi, T. S. Balaban, Eur. J. Inorg. Chem. (2012) 5915-5920.

[17] D. Gao, G. Canard, M. Giorgi, P. Vanloot, T. S. Balaban, Eur. J. Inorg. Chem. (2013) 279287.

[18] J. I. Setsune, A. Tsukajima, J. Watanabe, Tetrahedron Lett. 47 (2006) 1817-1820.

[19] G. Pomarico, X. Xiao, S. Nardis, R. Paolesse, F. R. Fronczek, K. M. Smith, Y. Fang, Z. Ou, K. M. Kadish, Inorg. Chem. 49 (2010) 5766-5774.

[20] D. L. Flint, R. L. Fowler, T. D. LeSaulnier, A. C. Long, A. Y. O’Brien, G. R. Geier, J. Org. Chem. 75 (2010) 553-563.

[21] R. Costa, G. R. Geier, C. J. Ziegler, Dalton Trans. 40 (2011) 4384-4386.

[22] S. Nardis, G. Pomarico, F. R. Fronczek, M. G. H. Vicente, R. Paolesse, Tetrahedron Lett. 48 (2007) 8643-8646.

[23] D. Sakow, D. Baabe, B. Böker, O. Burghaus, M. Funk, C. Kleeberg, D. Menzel, C.

Pietzonka, M. Bröring, Chem. Eur. J. 20 (2014) 2913-2924.

[24] M. Ethirajan, Y. Chen, P. Joshi, R. K. Pandey, Chem. Soc. Rev. 40 (2011) 340-362.

[25] M. Stefanelli, J. Shen, W. Zhu, M. Mastroianni, F. Mandoj, S. Nardis, Z. Ou, K. M. Kadish, F. R. Fronczek, K. M. Smith, R. Paolesse, Inorg. Chem. 48 (2009) 6879-6887.

[26] P. Świder, A. Nowak-Król, R. Voloshchuk, J. P. Lewtak, D. T. Gryko, W. Danikiewicz, J. Mass Spectrom. 45 (2010) 1443-1451.

[27] J. Wojaczyński, M. Duszak, L. Latos-Grazyński, Tetrahedron 69 (2013) 10445-10449.

[28] C. Tardieux, C. P. Gros, R. Guilard, J. Heterocycl. Chem. 35 (1998) 965-970.

[29] G. R. Geier, J. F. B. Chick, J. B. Callinan, C. G. Reid, W. P. Auguscinski, J. Org. Chem. 69 (2004) 4159-4169. 
[30] For an extensive study of free-base corrole conformation, see: J. Capar, J. Conradie, C. M. Beavers, A. Ghosh, J. Phys. Chem. A. 119 (2015) 3452-3457.

[31] C. J. Ziegler, J. R. Sabin, G. R. Geier, V. N. Nemykin, Chem. Comm. 48 (2012) 4743-4745.

[32] K. E. Thomas, A. B. Alemayehu, J. Conradie, C. M. Beavers, A. Ghosh, Inorg. Chem. 50 (2011) 12844-12851.

[33] K. E. Thomas, C. M. Beavers, A. Ghosh, Mol. Phys. 110 (2012) 2439-2444.

[34] Aurophilic interactions of approximately 4.93-4.35 Å have been observed in a crystal structure of a gold triarylcorrole. ${ }^{\text {[Error! Bookmark not defined.a] }}$

[35] A. B. Alemayehu, L.-K. Hansen, A. Ghosh, Inorg. Chem. 49 (2010) 7608-7610.

[36] K. E. Thomas, H. Vazquez-Lima, Y. Fang, Y. Song, K. J. Gagnon, C. M. Beavers, K. M. Kadish, A. Ghosh, Chem. Eur. J. 21 (2015) 16839-16847.

[37] I. H. Wasbotten, T. Wondimagegn, A. Ghosh, J. Am. Chem. Soc. 124 (2002) 8104-8116. 
For Table of Contents only:

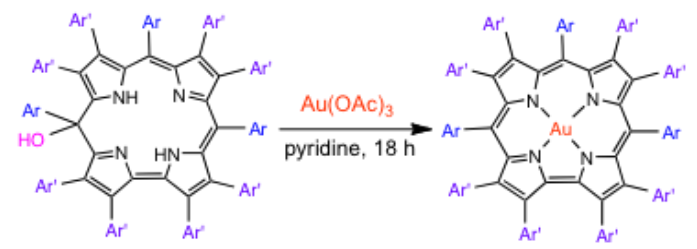

Synopsis: Free-base undecaarylisocorroles are presented as a new class of sterically hindered macrocyclic ligands. One of these has been complexed, with concomitant aromatization, to yield a gold(III) undecaarylcorrole. Both a free-base undecaarylisocorrole and the gold undecaarylcorrole were fully structurally characterized. The significant solubility of the gold complex appears to be related to the absence of aurophilic/metallophilic interactions. 
Table 1. Crystallographic data for $\mathrm{H}_{2}\left[\left(\mathrm{CF}_{3}\right)_{8} \mathrm{Me}_{3}(5-\mathrm{OH})\right]$.

\begin{tabular}{ccc}
\hline Sample & $\mathrm{H}_{2}\left[\left(\mathrm{CF}_{3}\right)_{8} \mathrm{Me}_{3}(5-\mathrm{OH})\right]$ & $\mathrm{Au}\left[\left(\mathrm{CF}_{3}\right)_{8} \mathrm{H}_{3}\right]$ \\
\hline Chemical formula & $\mathrm{C}_{96} \mathrm{H}_{56} \mathrm{~F}_{24} \mathrm{~N}_{4}$ & $\mathrm{C}_{95} \mathrm{H}_{51} \mathrm{~F}_{24} \mathrm{~N}_{4} \mathrm{Cl}_{4} \mathrm{Au}$ \\
Formula mass & 1737.44 & 2043.16 \\
Crystal system & Triclinic & Triclinic \\
Space group & $P 1$ & $P-1$ \\
$\lambda(\AA)$ & 0.7749 & 0.7749 \\
$a(\AA)$ & $12.783(3)$ & $15.4998(6)$ \\
$b(\AA)$ & $18.085(4)$ & $16.8410(6)$ \\
$c(\AA)$ & $18.600(4)$ & $16.9639(6)$ \\
$\alpha($ deg. $)$ & $102.363(3)$ & $106.229(2)$ \\
$\beta($ deg. $)$ & $108.203(3)$ & $91.961(2)$ \\
$\gamma($ deg. $)$ & $96.468(3)$ & $106.901(2)$ \\
$Z$ & 2 & 2 \\
V $\left(\AA^{3}\right)$ & $3914.7(15)$ & $4035.8(3)$ \\
Temperature $(\mathrm{K})$ & $100(2)$ & $100(2)$ \\
Density $\left(\mathrm{g} / \mathrm{cm}^{3}\right)$ & 1.474 & 1.681 \\
Measured reflections & 40303 & 78866 \\
Unique reflections & 15237 & 29236 \\
Parameters & 1169 & 1256 \\
Restraints & 66 & 646 \\
$\mathrm{R}_{\text {int }}$ & 0.0670 & 0.0524 \\
$\theta$ range (deg.) & $2.587-28.553$ & $2.165-36.007$ \\
$\mathrm{R}_{1}$, wR R $_{2}$ all data & $0.0683,0.2226$ & $0.0459,0.1140$ \\
$\mathrm{~S}($ GooF) all data & 1.024 & 1.030 \\
Max/min res. Dens. $\left(\mathrm{e} / \AA^{3}\right)$ & $0.410 /-0.349$ & $2.151 /-1.956$ \\
\hline & &
\end{tabular}




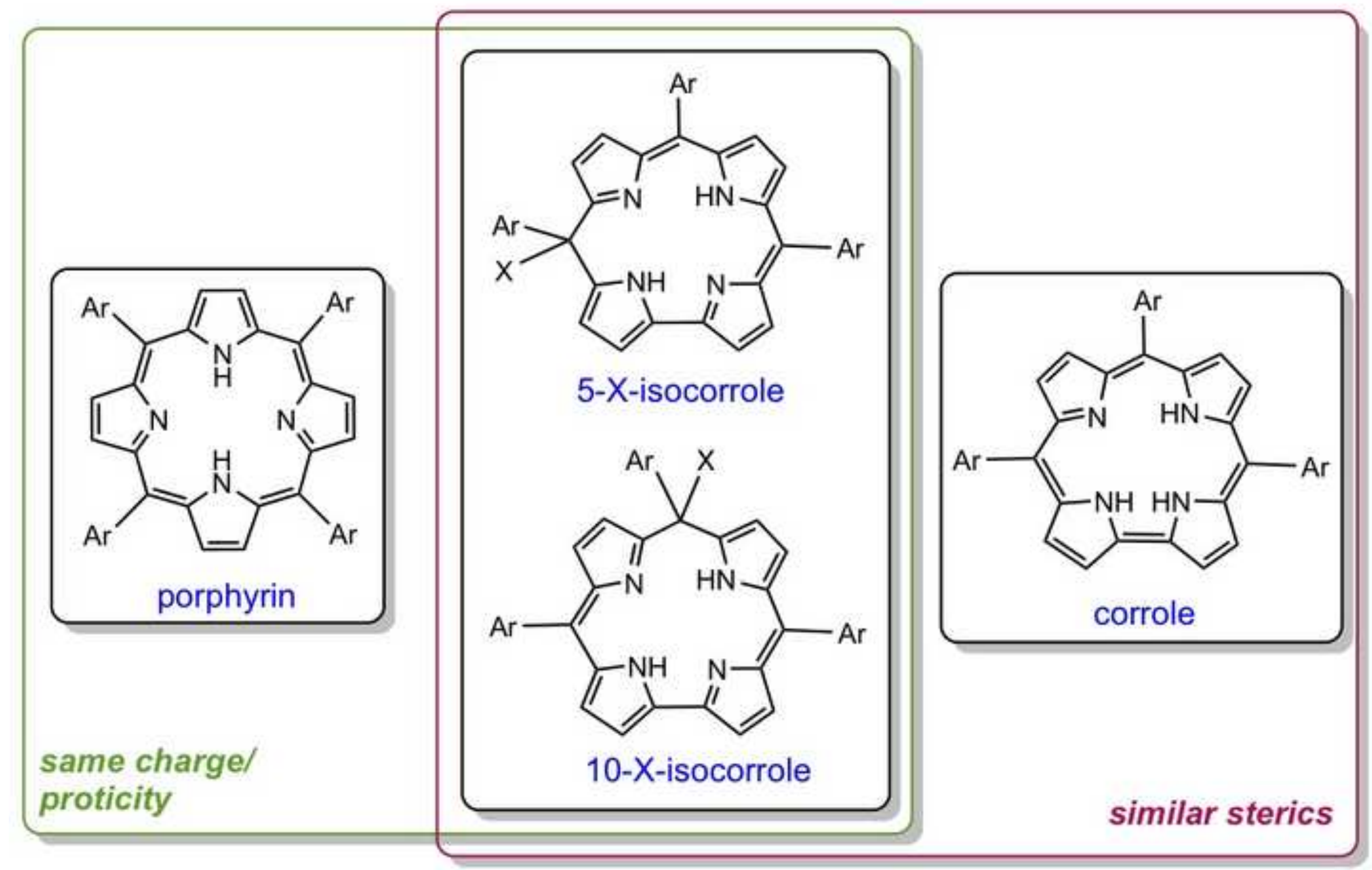




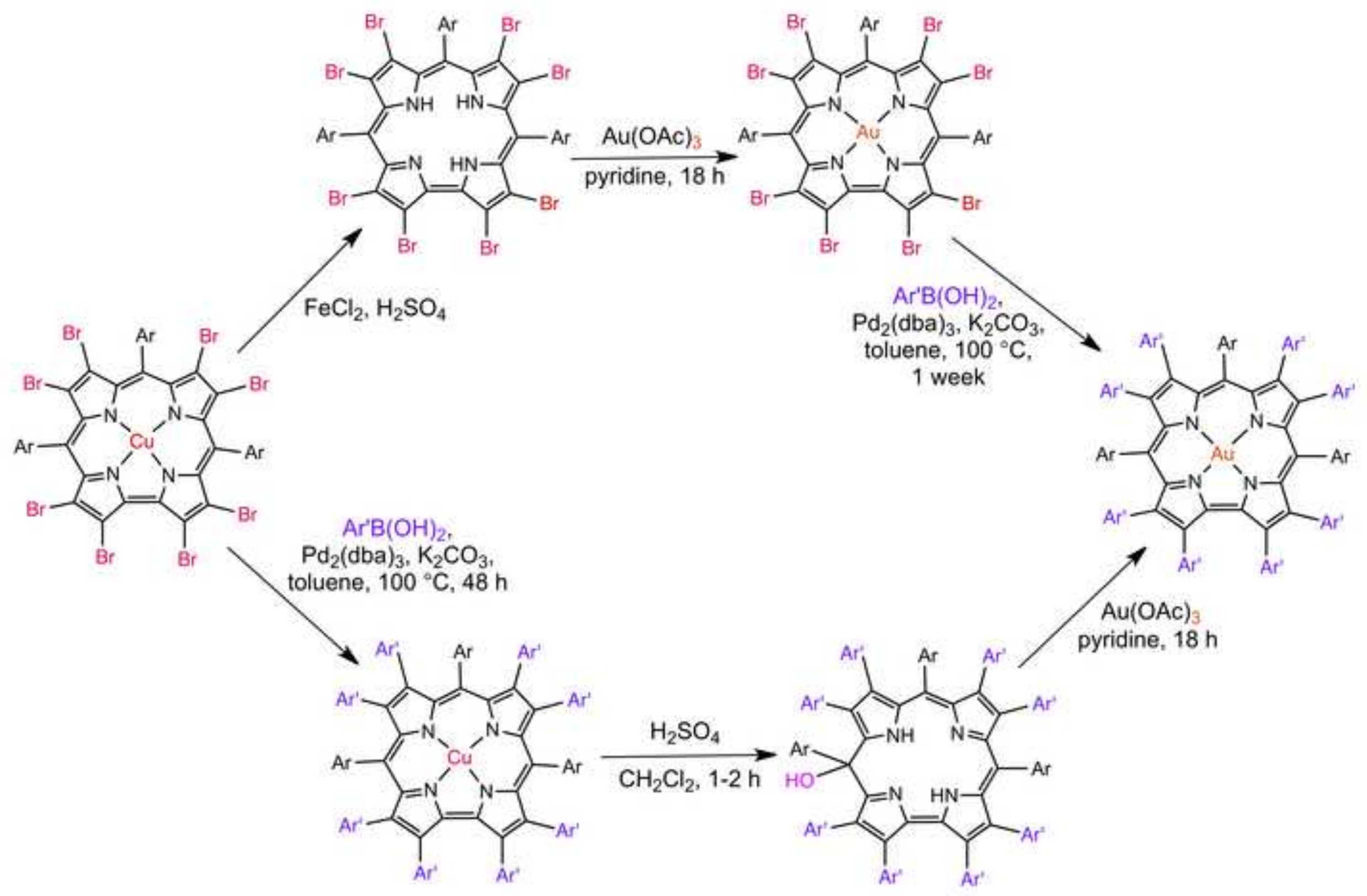



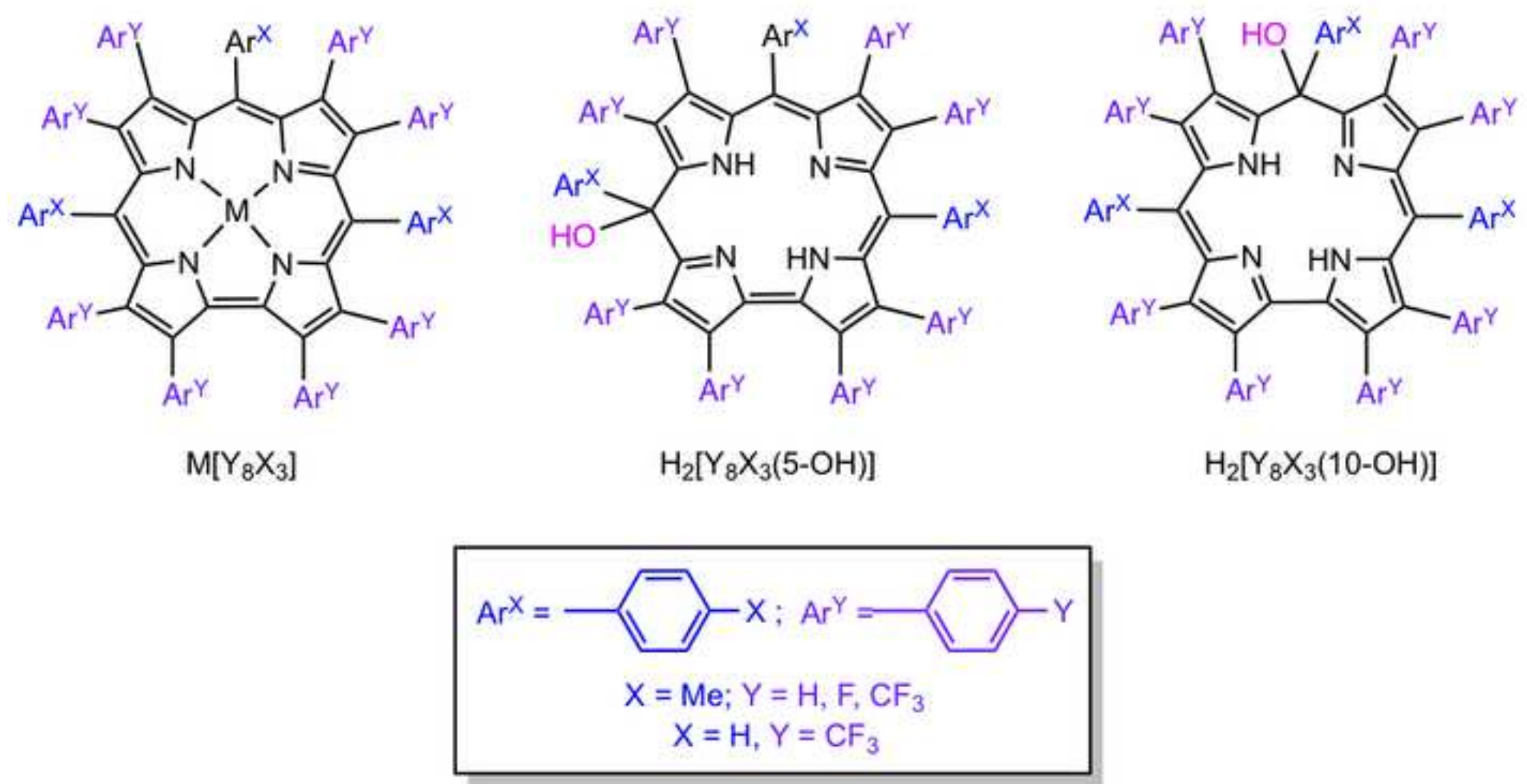


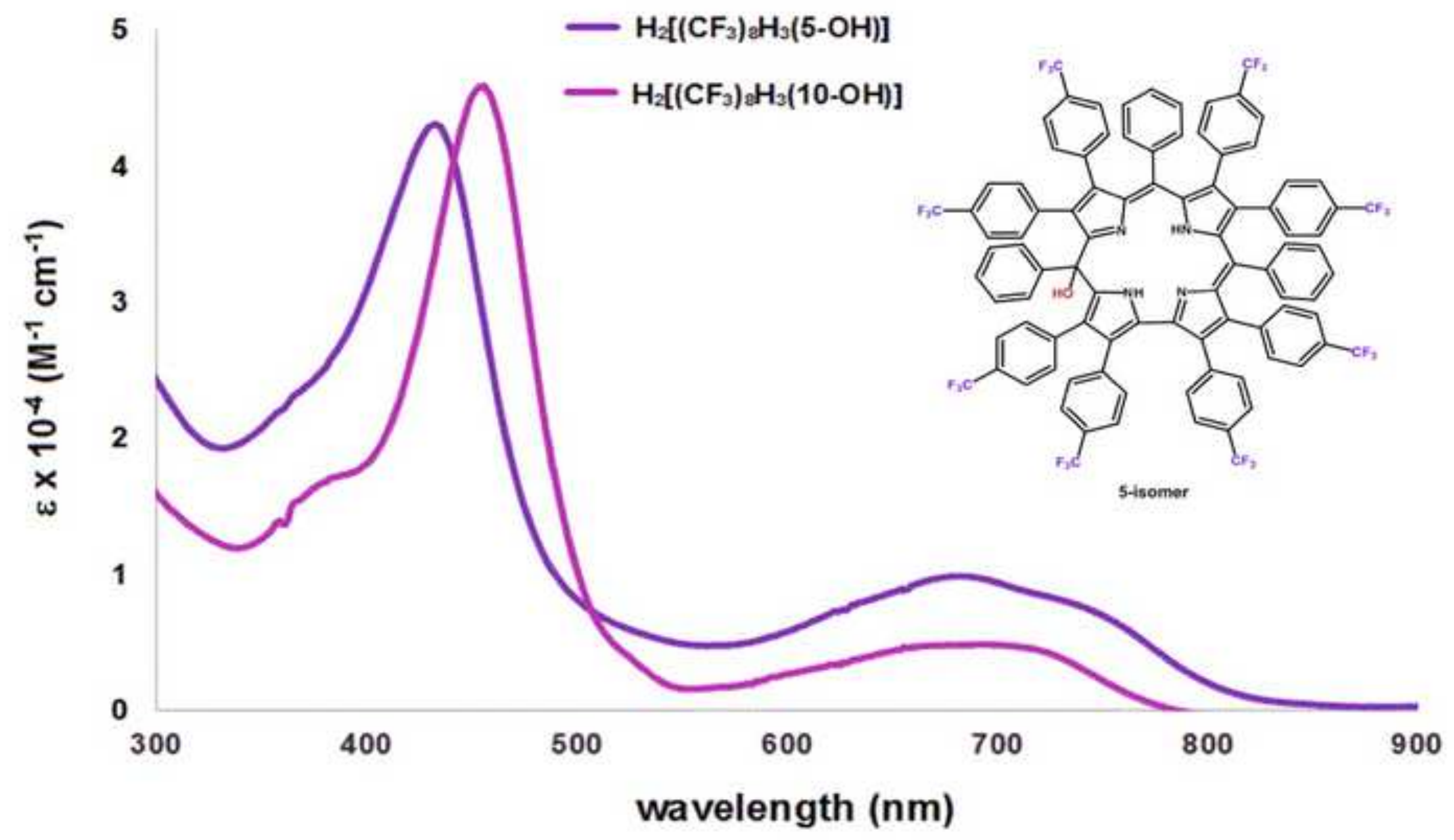




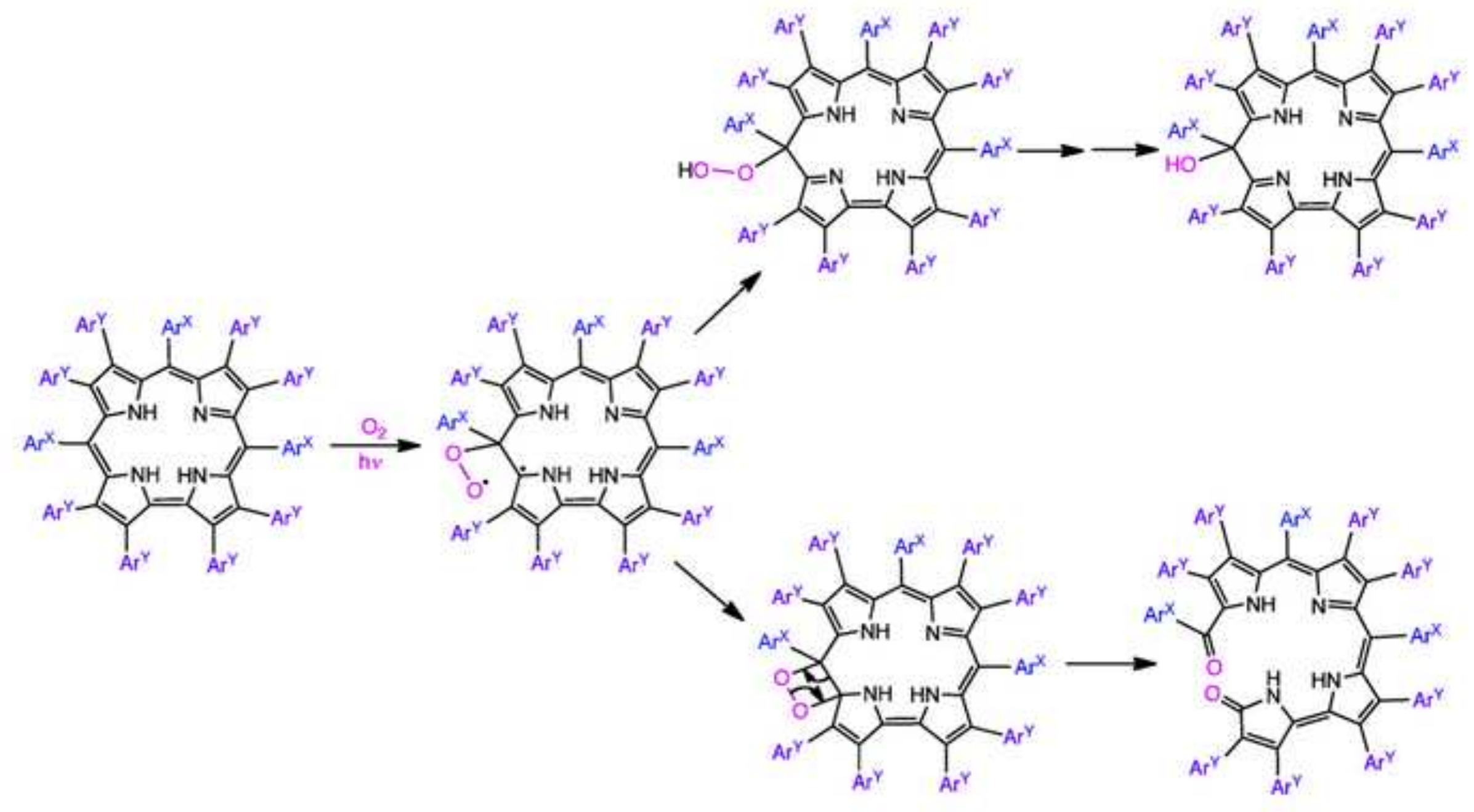



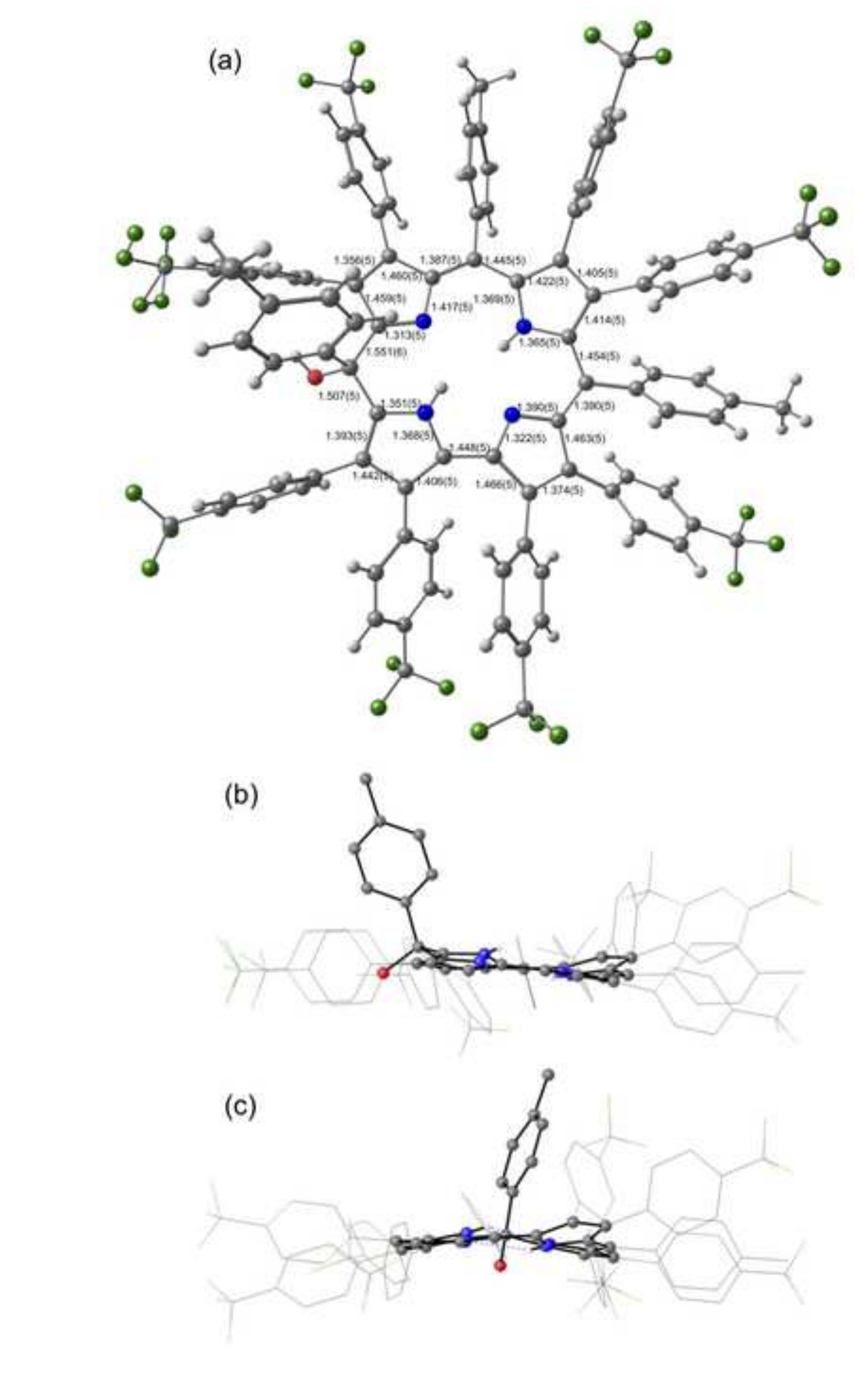

Figure 6

(b)

(c)

\section{Figure 6}

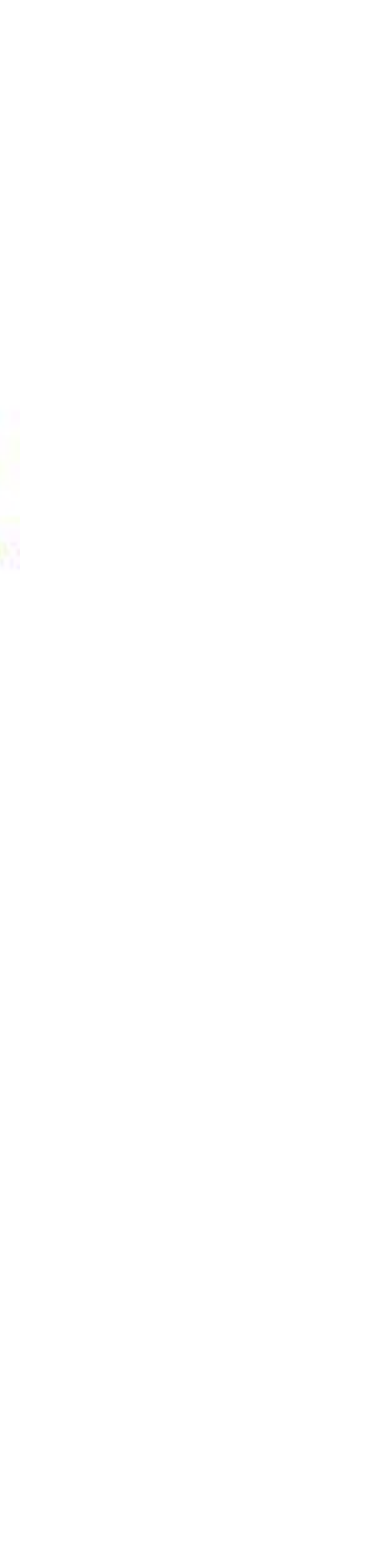




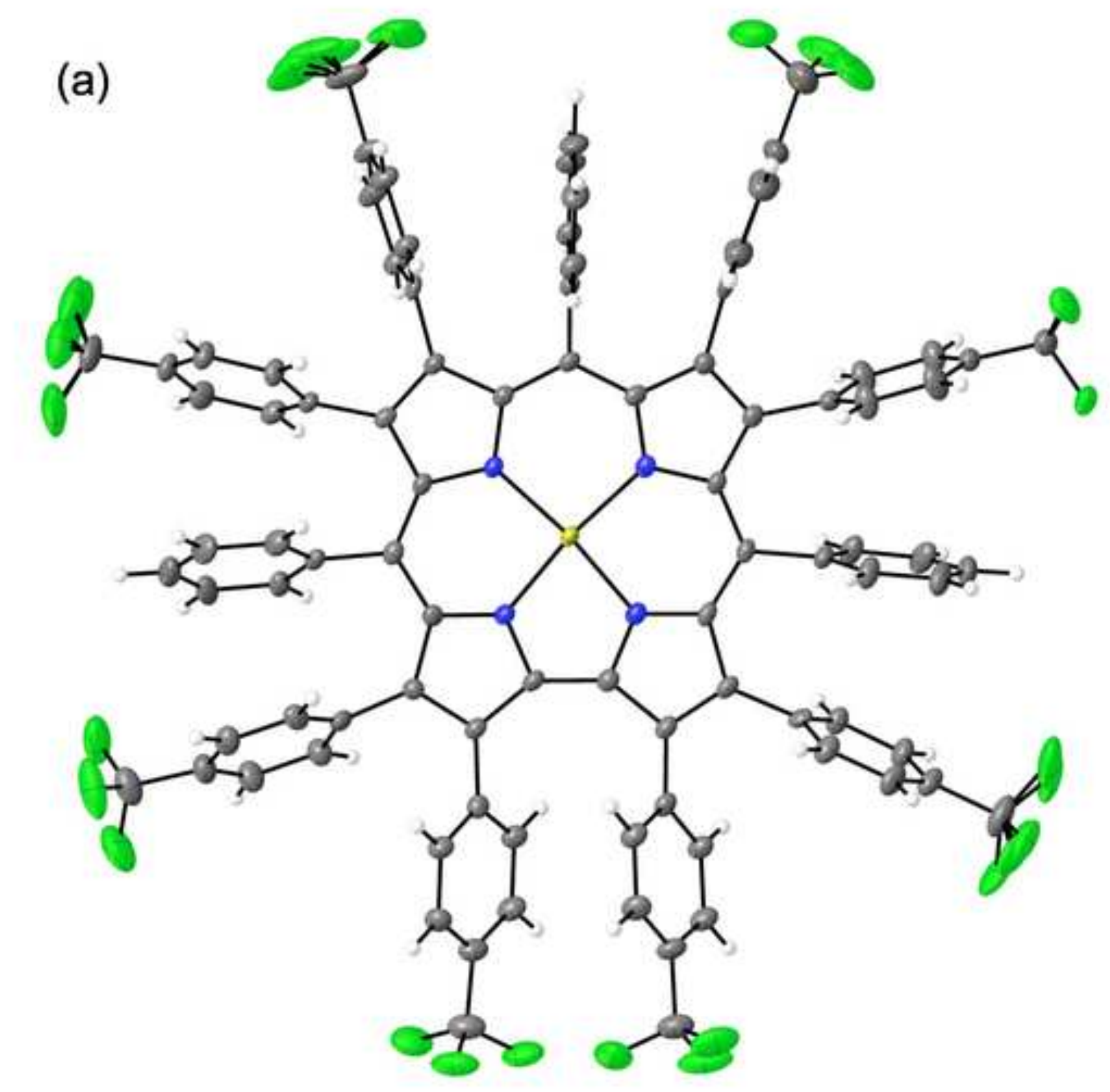

(b)

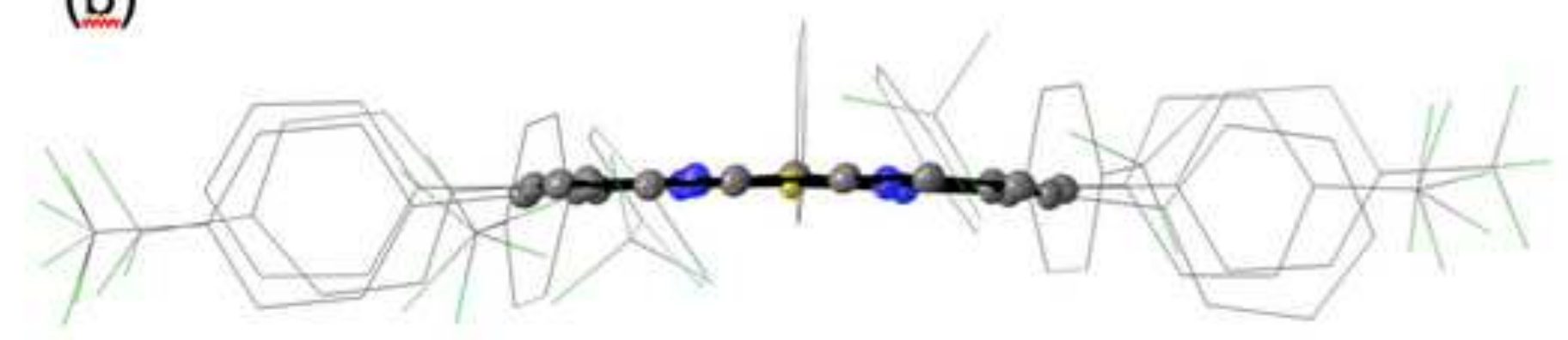

(a) 
For Table of Contents only:
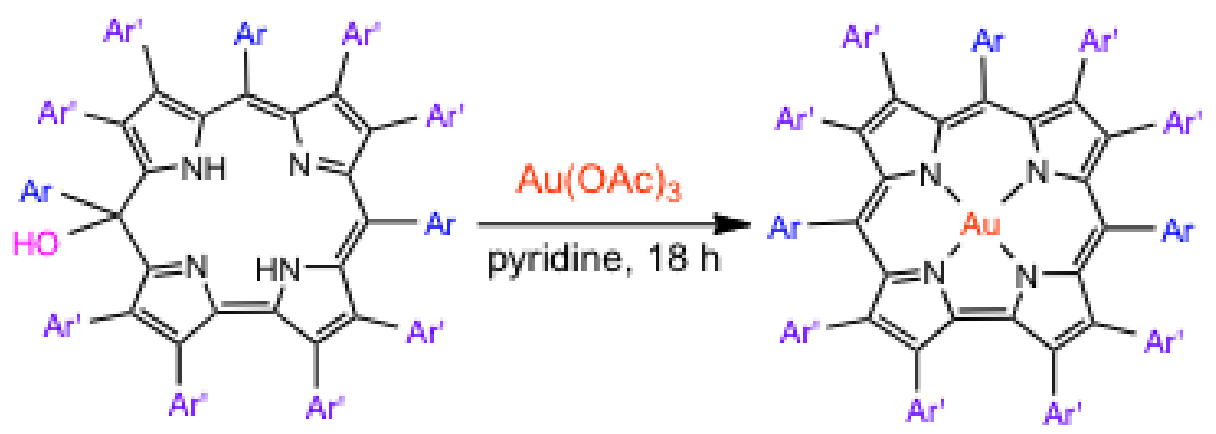

Synopsis: Free-base undecaarylisocorroles are presented as a new class of sterically hindered macrocyclic ligands. One of these has been complexed, with concomitant aromatization, to yield a gold(III) undecaarylcorrole. Both a free-base undecaarylisocorrole and the gold undecaarylcorrole were fully structurally characterized. The significant solubility of the gold complex appears to be related to the absence of aurophilic/metallophilic interactions. 